\title{
2-D Circulation Control Airfoil Benchmark Experiments Intended for CFD Code Validation
}

\author{
R.J. Englar*, G.S. Jones**, B.G. Allan**, J.C. Lin**
}

\begin{abstract}
A current NASA Research Announcement (NRA) project being conducted by Georgia Tech Research Institute (GTRI) personnel and NASA collaborators includes the development of Circulation Control (CC) blown airfoils to improve subsonic aircraft high-lift and cruise performance. The emphasis of this program is the development of $\mathrm{CC}$ active flow control concepts for both high-lift augmentation, drag control, and cruise efficiency. A collaboration in this project includes work by NASA research engineers, whereas CFD validation and flow physics experimental research are part of NASA's systematic approach to developing design and optimization tools for $\mathrm{CC}$ applications to fixed-wing aircraft. The design space for CESTOL type aircraft is focusing on geometries that depend on advanced flow control technologies that include Circulation Control aerodynamics. The ability to consistently predict advanced aircraft performance requires improvements in design tools to include these advanced concepts. Validation of these tools will be based on experimental methods applied to complex flows that go beyond conventional aircraft modeling techniques. This paper focuses on recent/ongoing benchmark high-lift experiments and CFD efforts intended to provide 2-D CFD validation data sets related to NASA's Cruise Efficient Short Take Off and Landing (CESTOL) study. Both the experimental data and related CFD predictions are discussed.
\end{abstract}

\section{Nomenclature}

$\mathrm{b}=$ span, in.

c, $\mathrm{C}=$ airfoil or wing chord, in

$\mathrm{CC}=$ Circulation Control

$\mathrm{C}_{\mathrm{p}}=$ pressure coefficient

$\mathrm{C}_{\mathrm{d}}, \mathrm{C}_{\mathrm{D}}=2-\mathrm{D}$ or 3-D drag coefficient

$\mathrm{C}_{\mathrm{l}}, \mathrm{C}_{\mathrm{L}}=2$-D or 3-D lift coefficient

$\mathrm{C}_{\mathrm{m}}=$ quarter-chord pitching moment coeff.

$\mathrm{C} \mu=$ jet momentum coefficient

$\mathrm{h}=$ jet slot height, in.

$\mathrm{LE}=$ leading edge

$\mathrm{m}=$ jet mass flow rate, slugs $/ \mathrm{sec}$

$\mathrm{NPR}=$ blowing nozzle pressure ratio

$\mathrm{q}=$ freestream dynamic pressure, $\mathrm{psf}$

$\mathrm{r}, \mathrm{R}_{\mathrm{te}}=$ jet surface radius

$\mathrm{Re}=$ Reynolds number

$\mathrm{S}=$ reference wing area, $\mathrm{ft}^{2}$

$\mathrm{T}=$ total or static temperature, ${ }^{\circ} \mathrm{R}$

$\mathrm{TE}=$ trailing edge

$\mathrm{U}=$ freestream or jet velocity, $\mathrm{ft} / \mathrm{sec}$

$\mathrm{w}=$ slot width, in.

$\mathrm{x}=$ chordwise location, in.

*Georgia Tech Research Institute, AIAA Associate Fellow; **NASA Langley Research Center, PhD, Researcher

Symbols:

$\alpha=$ angle of attack

$\rho=$ density

Subscripts:

$\mathrm{J}$, jet $=$ jet

$\mathrm{o}=$ total condition

inf $=$ freestream condition 


\section{Introduction}

Circulation Control pneumatic aerodynamic technology currently being developed (see Refs. 1,2 , and 3, for example) appears to offer the potential for a simple active flow control concept with few if any external moving components plus the ability to deliver very high force augmentations with relatively low blowing momentum $(\mathrm{C} \mu)$ input required. Add to this the fact that drag control is also possible merely by blowing variation, so that high drag can be generated for steep STOL approaches, or drag reduced for takeoff, climb-out, and cruise efficiency. Also, longitudinal pitch may be controlled by differential modulation of momentum from the upper and lower or fore and aft slots. To establish a data base for $\mathrm{CC}$ airfoils of this type, a three-year NASA NRA program was awarded to GTRI, with the intention that a generic CC airfoil be developed and evaluated for overall performance and parameter characterization by GTRI researchers at their test facilities. The same model was then to be transferred to NASA Langley Research Center for additional flow physics measurements to provide more detailed flow field characteristics. Data from the two tests were to provide validation data sets for CFD predictions conducted at both NASA and Georgia Tech. The current paper focuses mainly on the details of the experimental efforts and resulting data, but also presents representative CFD results.

\section{Subsonic 2-D CC Experiments}

The 2-D benchmark experimental databases that are described in this paper were conducted to provide physics and performance characteristics needed to improve the design tools used for advanced aircraft configurations. They are to yield a baseline set of reference data for $\mathrm{CC}$ pneumatic airfoils by which developing CFD codes can be validated. The typical CC airfoils of interest here are the circular-trailing-edge type, such as in Figure 1, where tangential blowing over the curved upper or lower trailing edges entrains the surrounding freestream flow field and dramatically augments or reduces (as desired) the airfoil's forces and moments (see for example, References 1 and 2). The 2-D CC effort is the cornerstone for 3-D efforts, since many of the CFD issues (e.g. boundary layer and jet separation, turbulence models, grid spacing, etc.) are common to both 2-D and 3-D computations (Ref. 3).

The fundamental generic CC airfoil geometry shown in Figure 1 utilizes both an upper and a lower surface blowing capability. This geometry was chosen as the representative benchmark airfoil contour for this 2-D effort because it is characteristically simple but has a large trailing

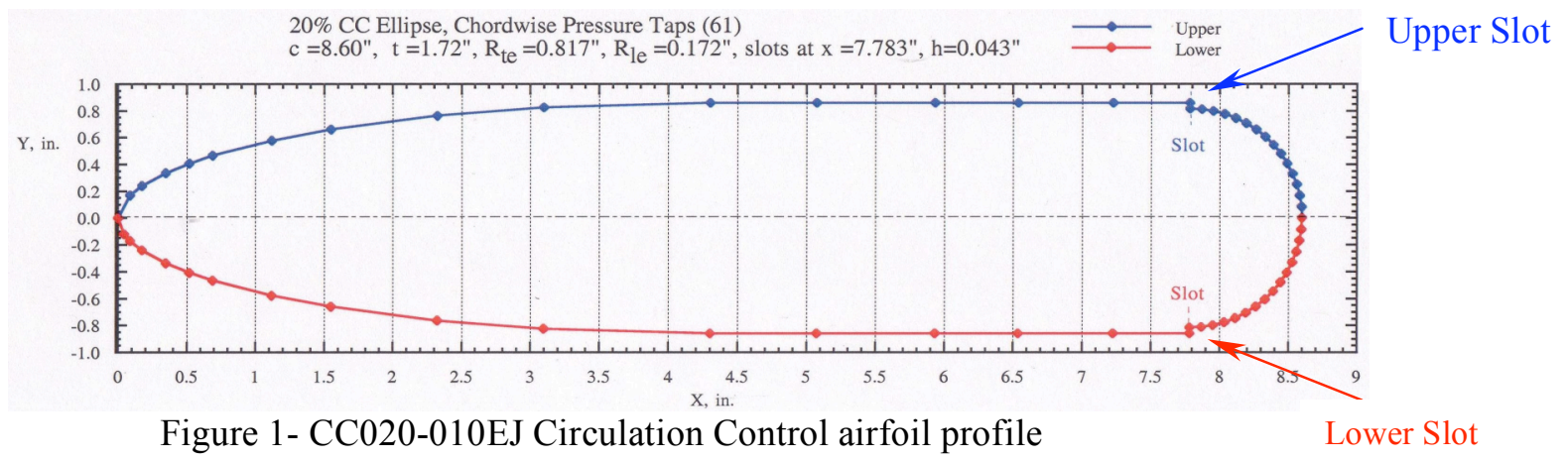


edge; this allows for accurate experimental measurements of jet properties and turning, which have been determined to be critical parameters for this validation effort. Lack of airfoil camber and aft curvature prior to the slot eliminate some flow separation issues, but not those at the trailing edge. The double-slotted trailing edge serves three purposes. As Ref. 4 notes, it is possible for the $\mathrm{CC}$ jet to turn too far onto the lower surface and thus generate suction (and negative lift) there; the lower jet can offset this with very-low-momentum blowing applied. Secondly, in cruise, the two jets can be blown equally at low momentum values to eliminate the bluff body separation and base drag of the thick trailing edge. Thirdly, this arrangement allows the generation of positive or negative pitching moment for trim and/or control by using differential blowing between the two slots. It is to be noted that this thick CC airfoil geometry is not proposed for any particular higher-speed subsonic fixed-wing aircraft, but merely as a generic source of representative data for CFD flow field simulation.

One of the requirements of CFD validation was to corroborate all the experimental data for CFD boundary conditions that include wind tunnel conditions, jet exit conditions, and model geometry. To do this, two wind tunnel tests that evaluated the same model (CC020-010EJ, Fig. 1) were utilized. The first test series was performed in the Georgia Tech Research Institute (GTRI) Model Test Facility (MTF). This series emphasized the performance characteristics of the airfoil and performed parametric studies of the slot heights on both upper and lower surfaces. It also investigated Reynolds number variation. The second test series was performed in the NASA LaRC Basic Aerodynamic Research Tunnel (BART). This series emphasized the detailed flow physics and outer flow field characteristics related to selected model configurations that include separation flow control and supercirculation flow control. Data from both series will be presented in the paper.

\section{Possible 2-D Test Concerns and Details}

The inherent problems associated with 2-D testing of high-lift airfoils (see Reference 5) are related to how the wind tunnel wall and model juncture flow field influence the twodimensionality of the test, as shown in Figure 2. Normally, large model aspect ratio and tunnelheight-chord ratio of the model reduce the influence of the juncture flows and wall interference. There was a 2-inch difference in the test section widths of the two tunnels used, resulting in a smaller exposed span for the BART facility. The 2-D aspect ratios (span/chord) for these tests were 3.49 for MTF and 3.26 for BART. Tunnel height-to-model-chord ratios were 5.0 for MTF and 4.6 for BART. Both tests utilized sidewall blowing to compensate for juncture flow separation (Ref. 5) where the wall boundary-layer velocity deficit can interact with the adverse pressure gradient near the blown trailing edge slot to produce vorticity and 3-D downwash variations. However, some 3-D vortical flows still remained at the wall model juncture at higher blowing conditions. This can impact the effective angle of attack and spanwise lift uniformity. To determine the influence of these vortical flows, a 3-D computation will be compared to a 2-D free air condition in the CFD analysis below.

In addition to wall juncture flow issues, there is an influence of the presence of wind tunnel walls on streamline turning during high-lift generation. A CFD calculation comparing the streamline turning with and without wind tunnel walls is shown in Figure 3, where the stream line restriction due to the walls is evident. 


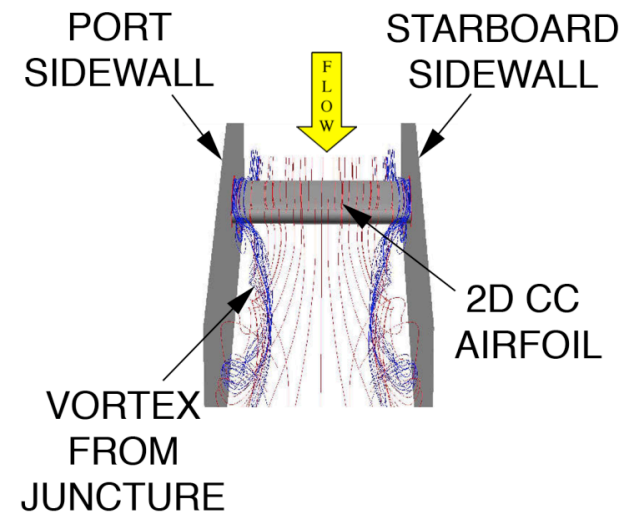

Figure 2- Streamlines highlighting vortical flows generated in the wall juncture region for a 2-D CC airfoil with $\mathrm{AR}=2.5$

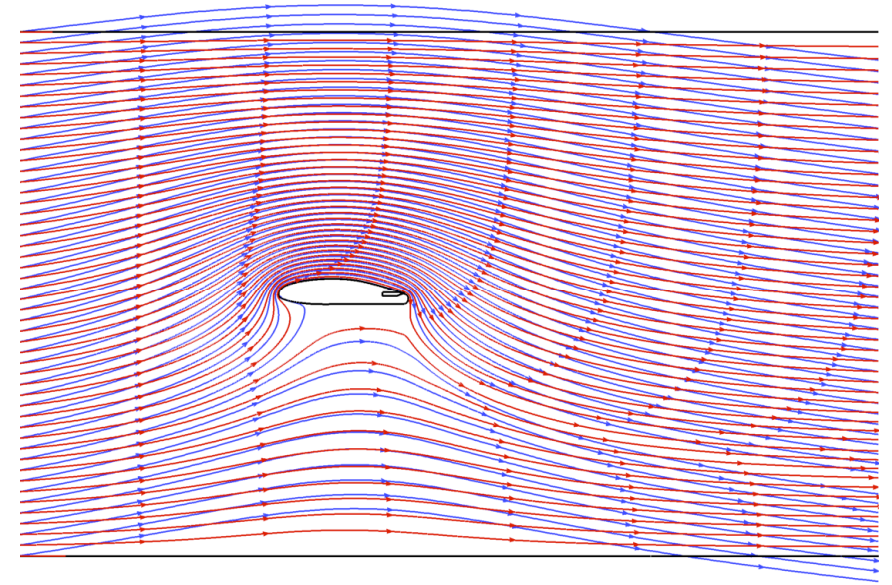

Figure 3- CFD evaluation of streamline turning with (red) and without (blue) wind tunnel walls

Both tunnel efforts measured model performance by integrating surface and wake pressures in addition to floor balance measurements. Nominally the model performance is characterized as a function of the momentum coefficient, $\mathrm{C} \mu$, defined as (below, left):

$$
\begin{aligned}
& \mathrm{C} \mu=\frac{\text { THRUST }}{\mathrm{qS}}=\frac{2 \mathrm{hw}}{\mathrm{Cb}} \frac{\rho_{\mathrm{JET}}}{\rho_{\infty}} \frac{\mathrm{U}_{\mathrm{JET}}^{2}}{\mathrm{U}_{\infty}^{2}} \\
& \mathrm{C} \mu=\frac{\text { THRUST }}{\mathrm{qS}}=\frac{\mathrm{mU} \mathrm{U}_{\mathrm{JET}}}{\mathrm{qS}}
\end{aligned}
$$

where

$$
\mathrm{U}_{\mathrm{JET}}=\sqrt{\frac{2 \gamma \mathrm{R}\left(\mathrm{T}_{0 \mathrm{JET}}\right)}{\gamma-1}\left(1-\left(\frac{\mathrm{P}_{\infty}}{\mathrm{P}_{0 \mathrm{JET}}}\right)^{\frac{\gamma-1}{\gamma}}\right)}
$$

and

$$
\mathrm{m}=\rho_{\mathrm{JET}} \mathrm{U}_{\mathrm{JET}}(\mathrm{h})(\mathrm{w})
$$

Possible errors associated with experimental determination of the momentum coefficient $\mathrm{C} \mu$ (Equations 1 and 2) for small-scale experiments are generally dominated by slot height $(\mathrm{h})$ measurement (Eq. 1) or by slot expansion under pressure. Using Equation 2 with measured mass flow (m) avoids slot height measurements and can minimize $\mathrm{C} \mu$ errors. This is acceptable for performance testing when system mass flow is accurately measured. However accurate measurement of slot height variation along the span is critical to the correlation of local mass flow at the slot exit when outer flow measurements are made. These local conditions are used for boundary conditions needed for CFD validation. Hot
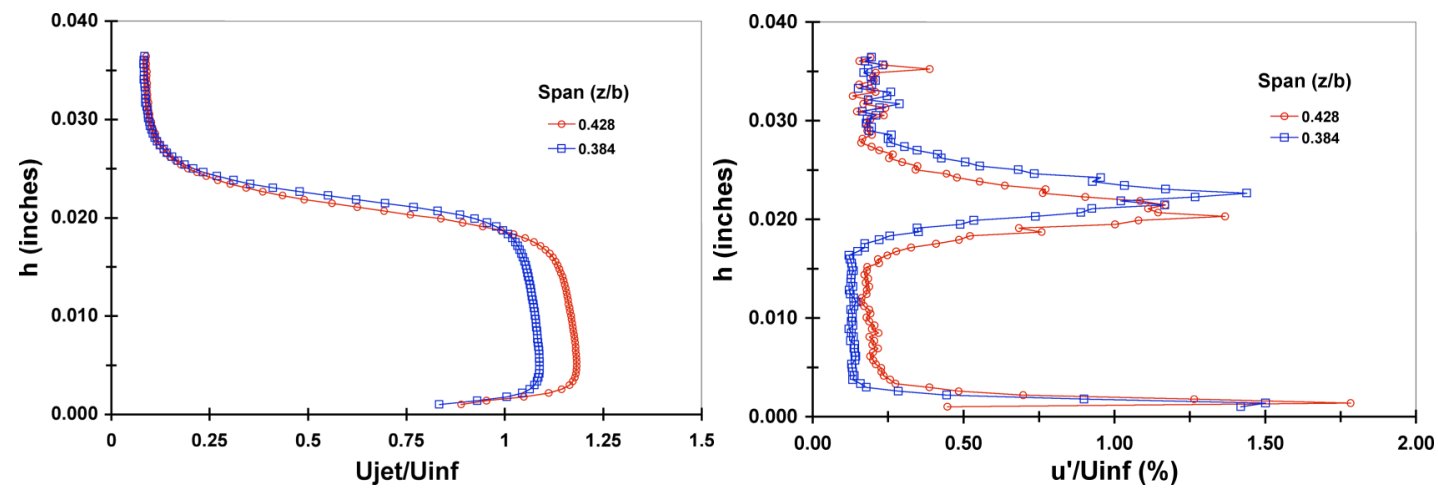

Figure 4- Typical hot wire surveys at $\mathrm{CC}$ jet exit, $\mathrm{U}=0$, and $\mathrm{h}_{\mathrm{NOMINAL}}=0.025$ " 
wire measurements such as those shown in Figure 4 are also used to characterize the slot height at the jet exit using turbulence profiles. These profiles highlight the mean velocity distribution and quantify any errors caused by the assumption of isentropic expansion for these wall-bounded jets (see Equation 3 above). An example of spanwise variations in model slot height using direct measurement techniques is shown in Figure 5 for the current $\mathrm{CC}$ model.

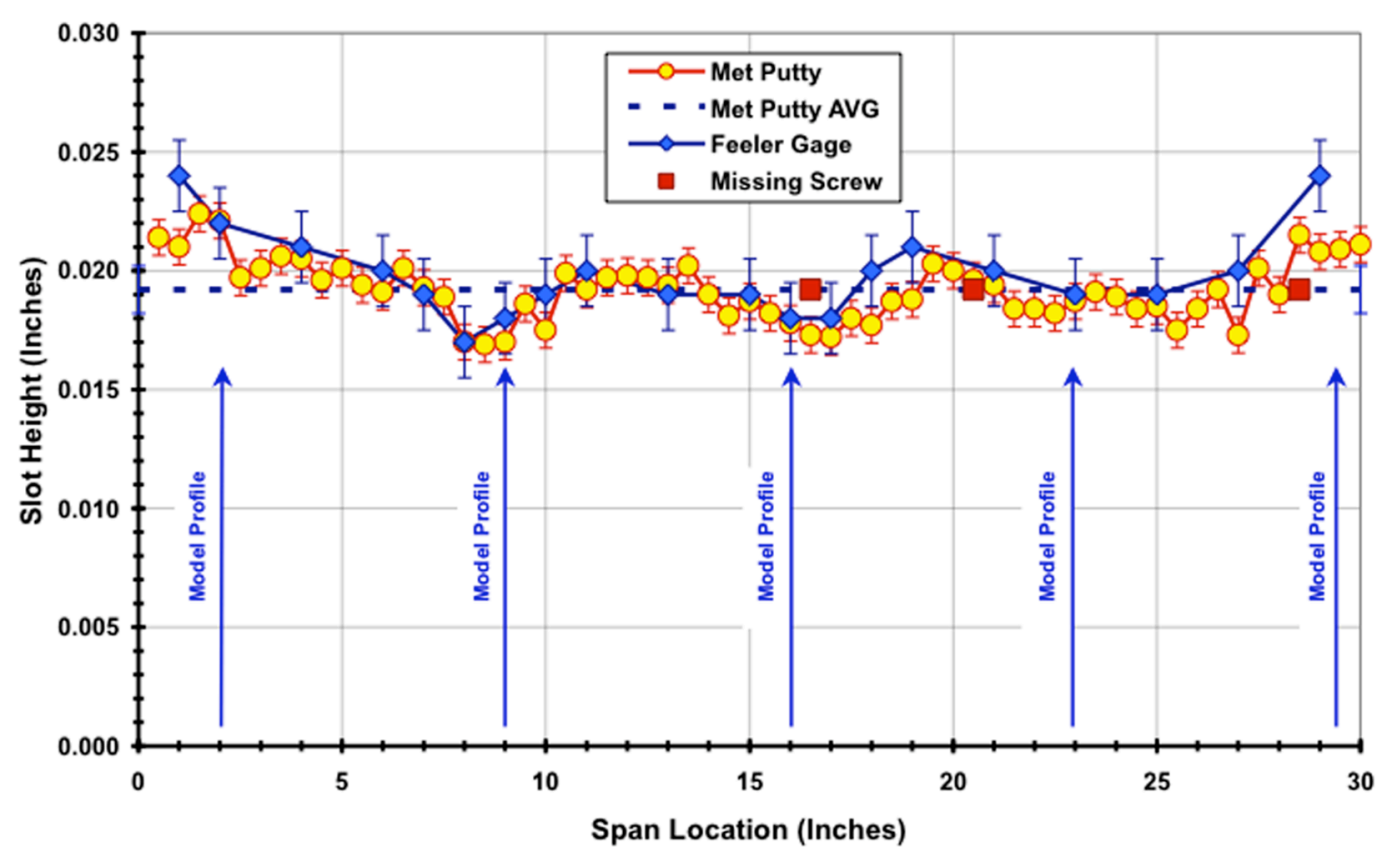

Figure 5- Comparison of slot height measurements at NASA BART using an inverse metrology putty technique and feeler gage, nominal $\mathrm{h}=0.018$ "

\section{2-D Experimental Results, Blowing OFF, GTRI}

The 2-D CC elliptic-leading-edge airfoil model based on the Figure 1 geometry is shown installed in the GTRI Model Test Facility in Fig. 6. Visible are the floor balance, the downstream wake rake, and floor/ceiling wall static pressure tap plates. Below the floor is a 6component strain gage balance and angle-of-attack turntable, plus two air supply lines for separate upper and lower blowing slots and additional air lines for the wall blowing system. . The model is 30 " in span with an 8.6" chord, and can be run blowing on or off at various blowing slot heights, Reynolds numbers, and angles of attack. Tares for any loads due to pressurizing these air lines were taken and removed from all blowing-on balance data.

Low-Reynolds-number effects without blowing were experimentally evaluated early in the program to determine the minimum usable tunnel flow conditions. There is clearly a Reynolds number effect due to the aft-facing slots, the leading edge, and/or the classic drop off of $C_{D}$ with Reynolds number for bluff bodies, as shown in Figure 7. (The trailing-edge radius of this $20 \%$ thick CC airfoil is $0.095 \mathrm{c}$ ). Here, the measured drag coefficient becomes constant at approximately $\mathrm{q}>12 \mathrm{psf}$ or $\operatorname{Re}>0.42 \times 10^{6}$; this thus became a guide for the dynamic pressure range of the remaining test. 


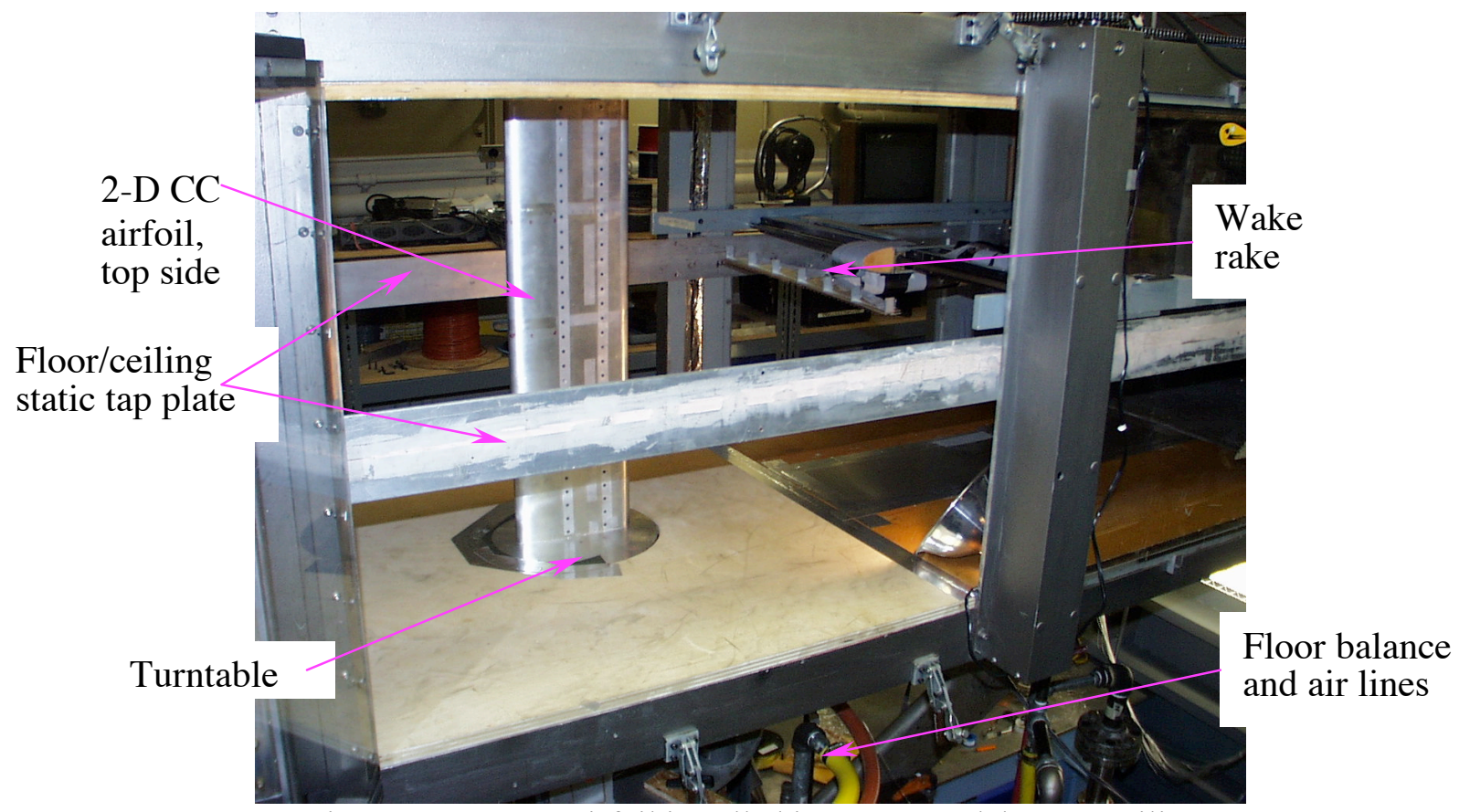

Figure 6- 2-D CC Airfoil installed in GTRI Model Test Facility
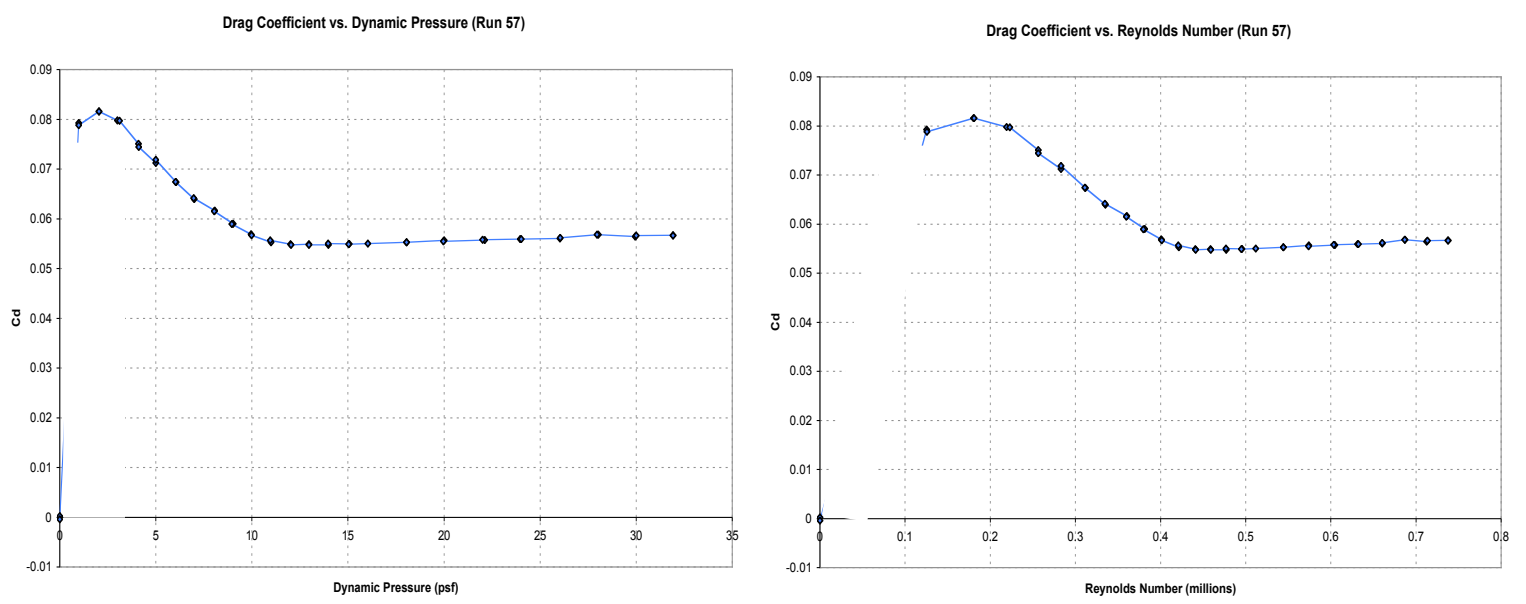

Figure 7- Drag variation with dynamic pressure and Reynolds number, $C \mu=0.0, \alpha=0^{\circ}$, balance data

The effect of Reynolds number on lift of this thick bluff airfoil was also measured, Fig. 8. The unblown lift curve slopes appear to become linear for $\mathrm{q}>11$ psf, indicating that most of the following test conditions should be run above that q range. Figure 8 shows examples of Reynolds number effects on the lift slope without blowing. Relatively small stall-hysteresis effects with angle of attack variation are also noted.

Figure 9 shows MTF lift results with variation in measuring techniques for unblown $C_{1}$ versus $\alpha$, running at $\mathrm{q}=20 \mathrm{psf}\left(\operatorname{Re} \sim 0.57 \times 10^{6}\right)$. Note that the floor-balance ("bal") and airfoil-surfacestatic-pressure-integration techniques at mid-span ("b/2 Cp") yielded similar lift results, but there is a discrepancy with the lift from wind-tunnel-wall-static-pressure-integration technique ("wall"). 


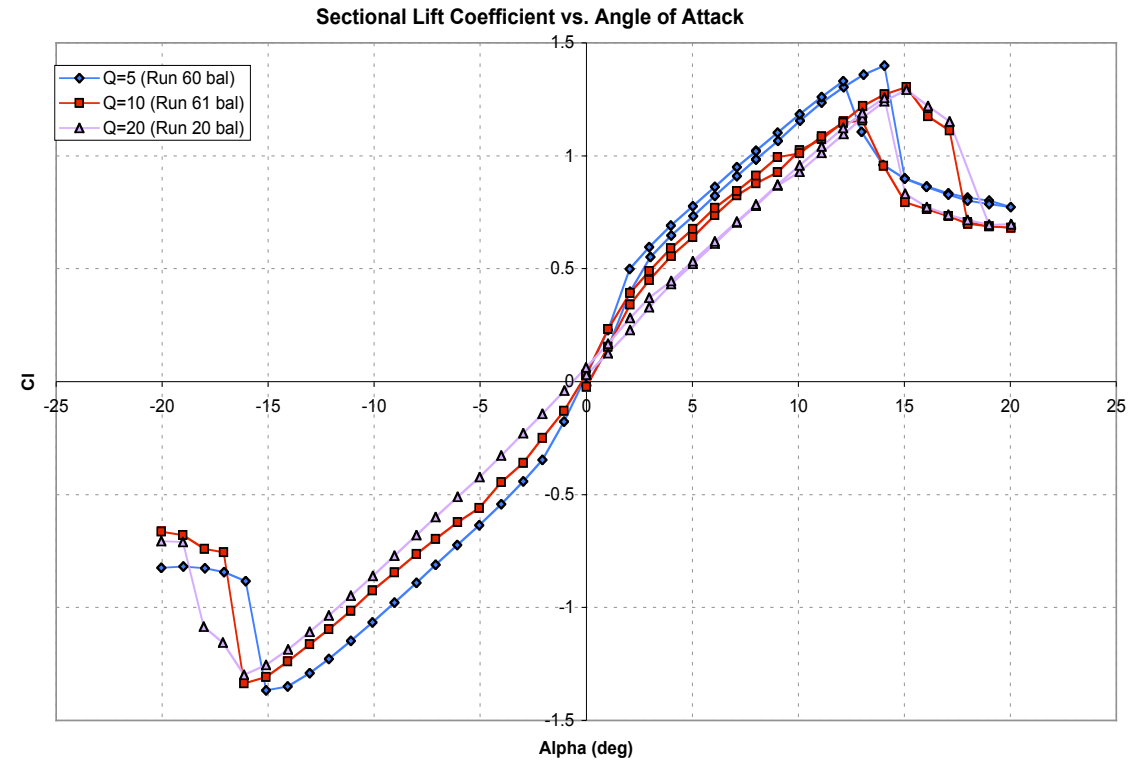

Figure 8- Lift Variation with angle of attack and Reynolds Number, $\mathrm{C} \mu=0$, balance data

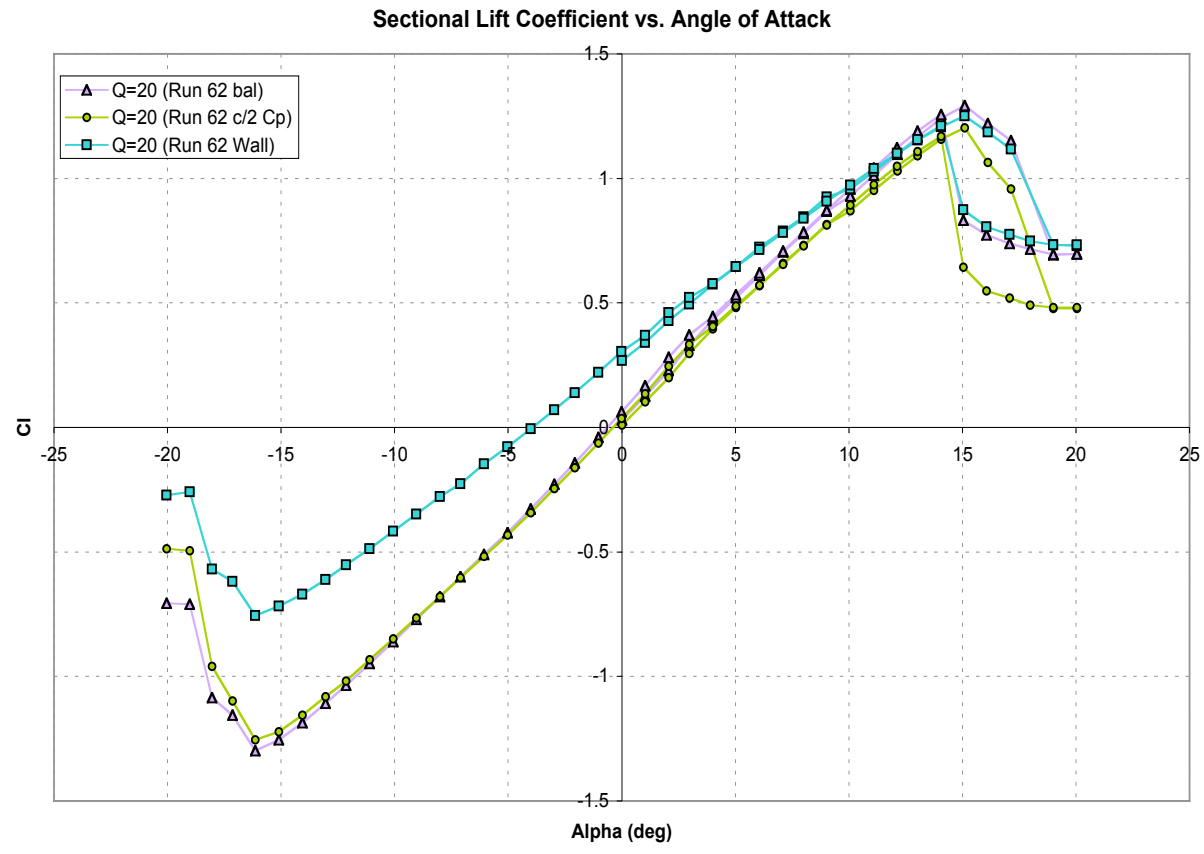

Figure 9- Lift Variation with various measuring techniques

It was found (see Figure 10) that the $C_{p}$ distributions along the wind tunnel walls did not converge to $\mathrm{C}_{\mathrm{p}}=0$ as anticipated far upstream or downstream in the tunnel because the pressuremeasuring strips along the walls were not long enough, and that the integrated areas were thus incomplete (these data are for blown models at $\alpha=0^{\circ}$ ). 


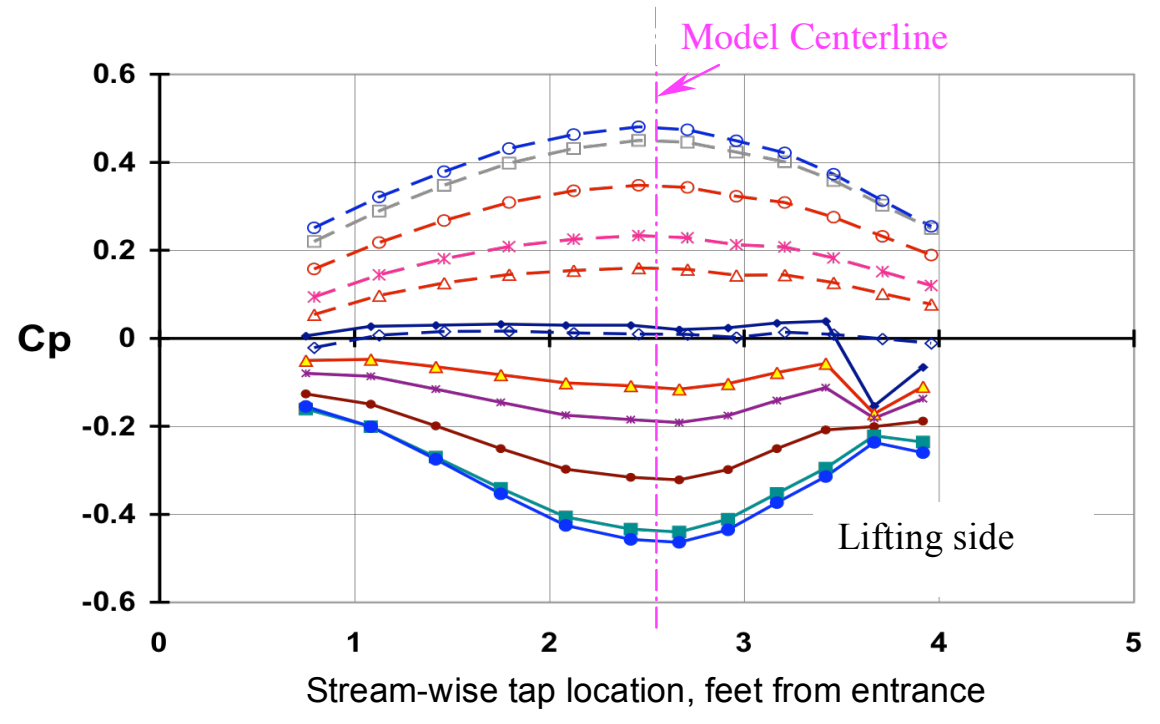

Figure 10- Wind tunnel wall pressure signatures for $0<\mathrm{C} \mu<0.4$

\section{2-D Experimental Results, Blowing ON, GTRI}

The initial unblown investigations above were then followed by variations in the blowing parameter $\mathrm{C} \mu$ and variations of slot height (and number of slots) plus angle of attack. The degree of static jet turning (nearly $180^{\circ}$ from the slot) due to blowing increase is seen in Fig 11a, for $\mathrm{q}=0 \mathrm{psf}$. This turning is seen to be reduced somewhat when the freestream is present (Fig. $11 \mathrm{~b}, \mathrm{q}=5 \mathrm{psf})$. Fig. 11c shows a lack of aft flow turning when blowing is terminated.

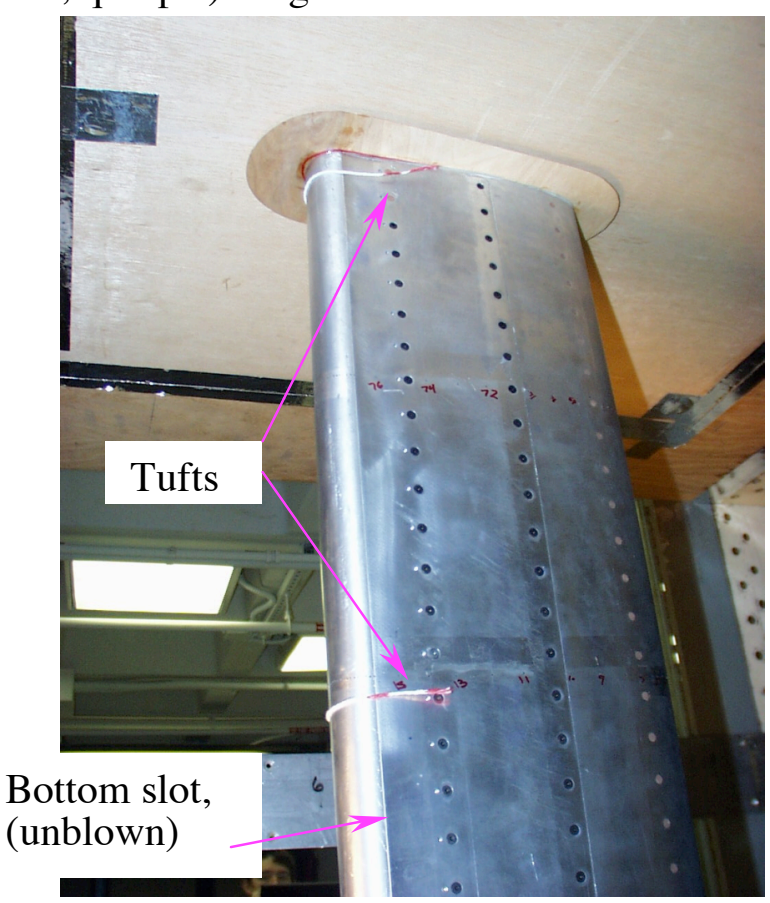

a. $q=0$ psf, $\alpha=0^{\circ}$

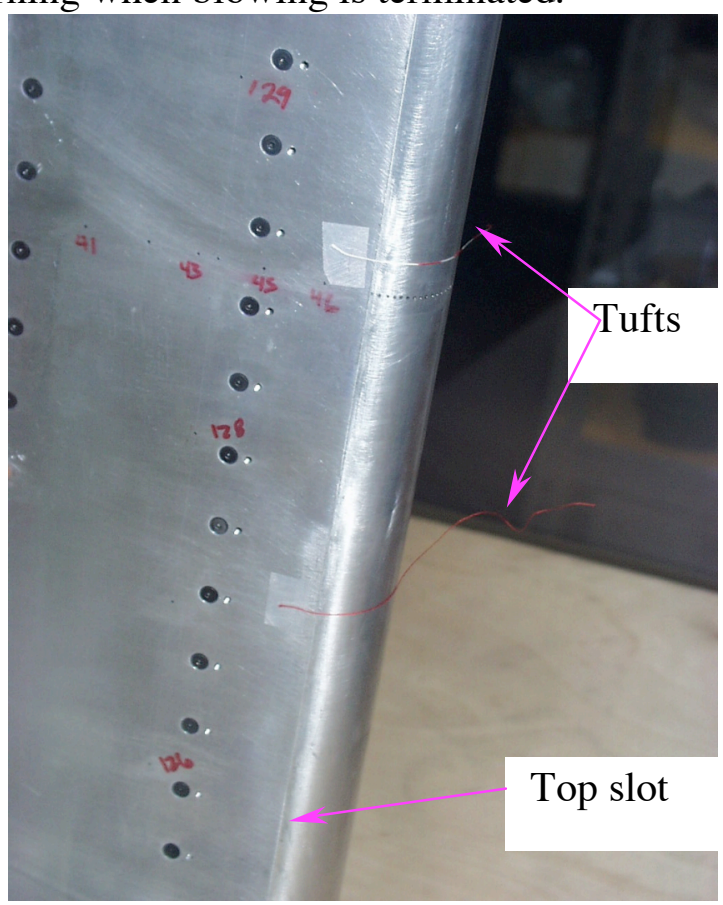

b. $q=5$ psf, $\alpha=0^{\circ}, C \mu=0.3$

Figure 11- Jet turning due to upper slot blowing 


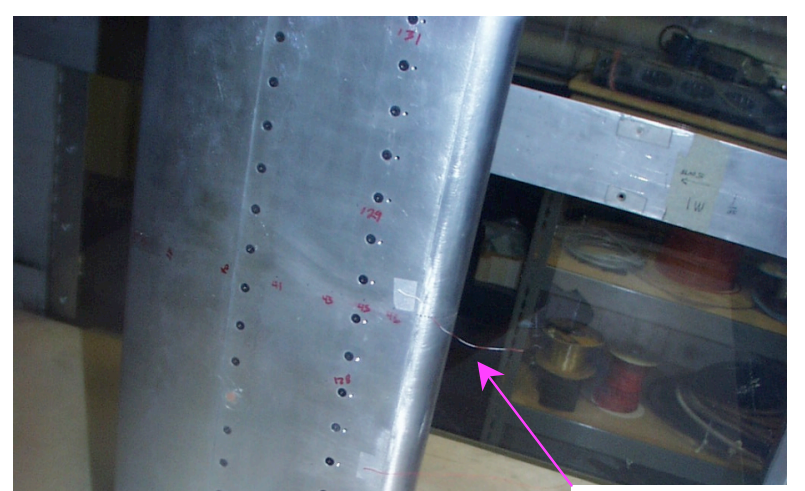

Unblown tuft

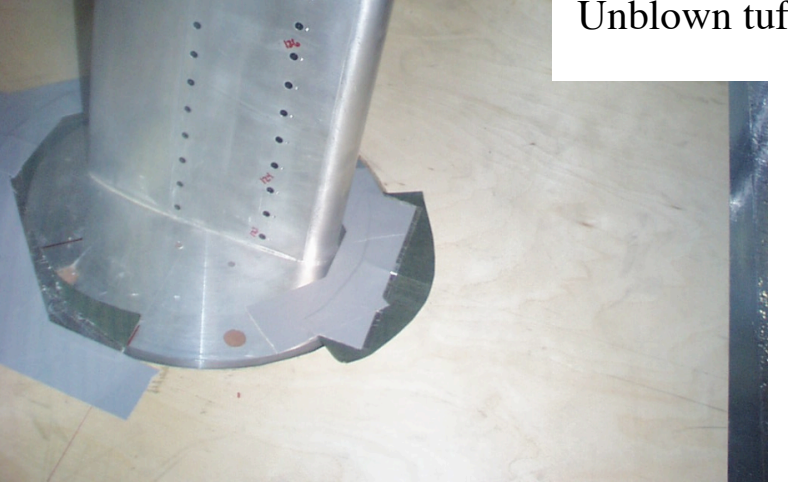

c. $\mathrm{q}=5 \mathrm{psf}, \mathrm{C} \mu=0.0$

Figure 11 (continued)- Jet turning without upper slot blowing

When higher blowing was initiated, an interesting issue of apparent $C \mu$-stall $\left(C_{1}\right.$ dropoff as $C \mu$ is increased) was found. Figure 12 shows $\mathrm{Cp}$ distributions at constant $\mathrm{C} \mu$ values just before and just after this premature stall $(\mathrm{C} \mu \sim 0.36 \rightarrow 0.37)$, indicated by leading-edge and trailing edge Cp dropoff. This phenomenon was corrected by fixing boundary layer transition on the lower surface (x/c $\sim 0.03$ ) where the stagnation point impacted the airfoil at these higher $\mathrm{C} \mu$ values. "Movies " of this measured phenomenon will be shown in the presentation of this data. Figure 13 shows the resulting lift loss due

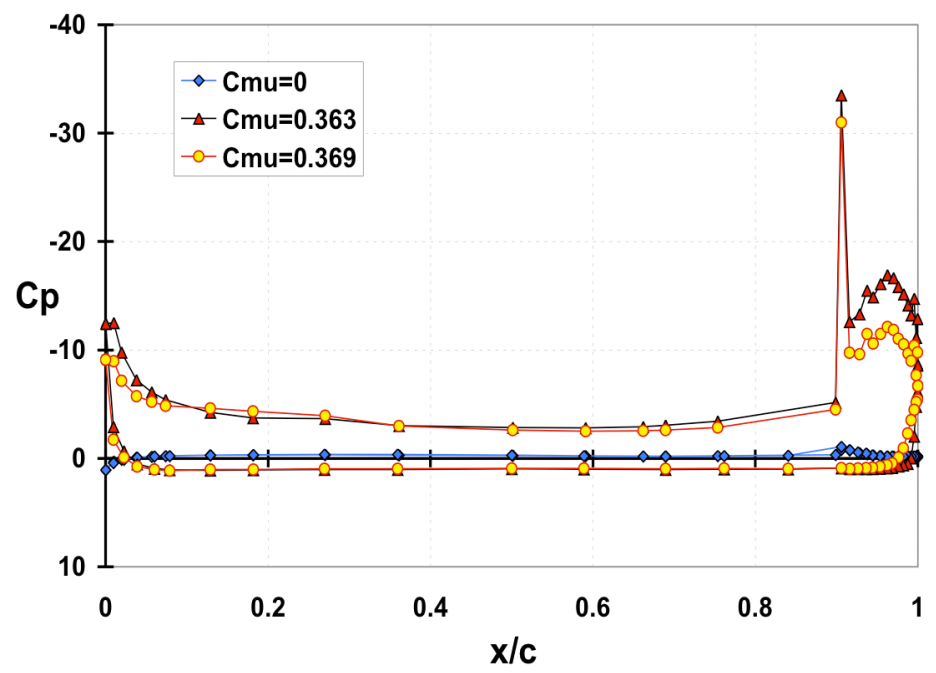

Figure 12- Surface pressure distributions highlight premature stall that is an effect of free transition. to this leading-edge separation. Whereas the lift coefficient did continue to increase with blowing, it left a lift deficit that required much additional blowing input before the lift loss was 
recovered. A C $\mu$ hysteresis is also noted here, where the reduction of blowing does not follow the same curve as the increase when this LE separation is involved. Also seen here in Figure 13 is the difference in measurement techniques. The half-span and the $3 / 4$-span pressure data are very much in agreement at the $\mathrm{C} \mu$ stall, thus indicating span-wise uniformity and good 2-D flow.

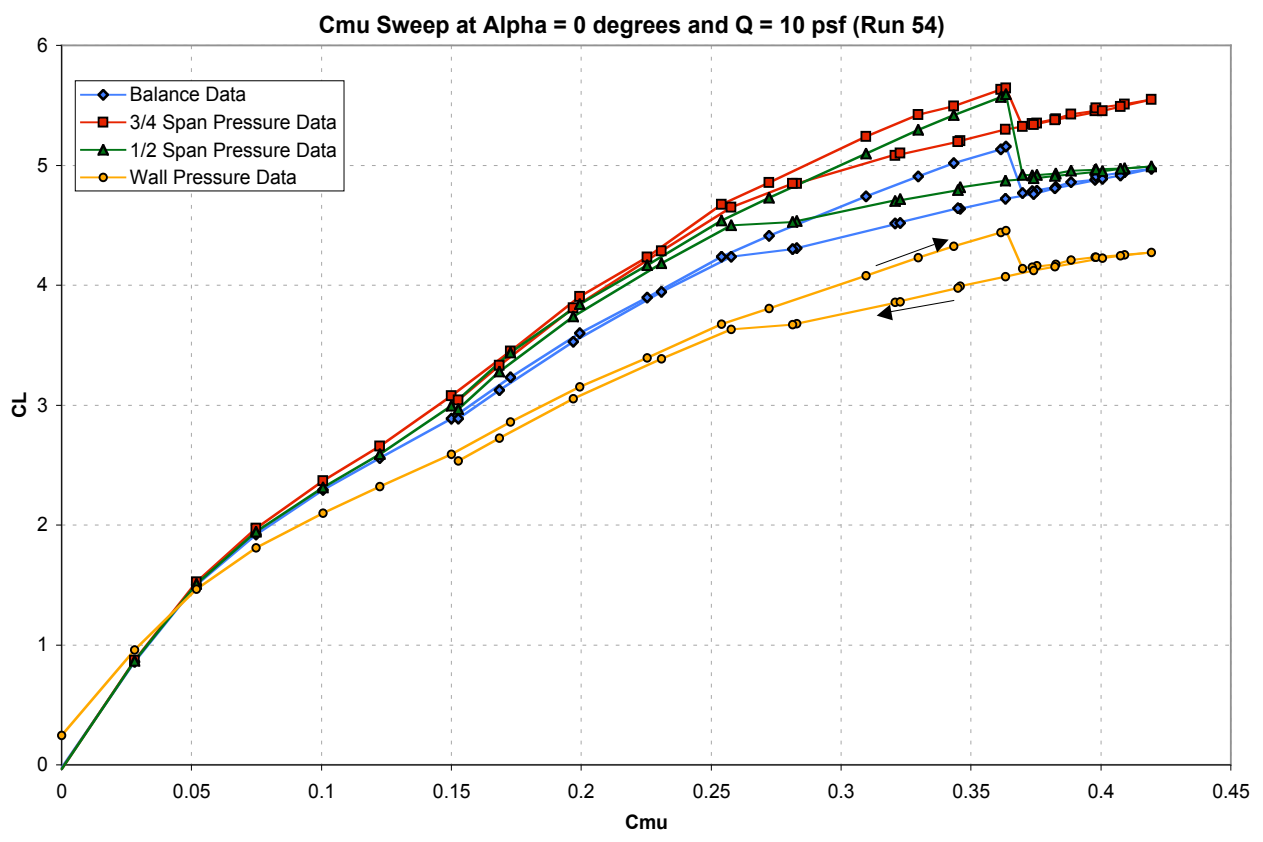

Figure 13- Lift loss due to LE separation as $C \mu$ is increased, $\alpha=0^{\circ}$

This leading-edge phenomenon was later investigated and confirmed during the NASA BART test, and should be mentioned now. Surface flow patterns were determined through oilflow visualization using a mixture of titanium dioxide and 5-centistoke silicone oil. Both upper and lower surfaces of the $\mathrm{CC}$ airfoil were covered with black contact paper upstream and up to the blowing-slot location. The sidewall juncture region (tunnel floor) adjacent to the model was covered with the contact paper as well. The oil mixture was then brushed onto the contact paper to obtain an overall flow pattern. Typically, this method worked quite well in identifying a line of relatively narrow leading edge separation bubble as well as the juncture flow regions on the model and the tunnel wall, as exemplified in Figures 14 and 15 for the blowing case of $C \mu=0.3$. Even with a boundary-layer trip installed near the leading edge of the lower surface, there remained a small and persistence region of separation bubble towards the leading edge of the upper surface for the blowing cases.

Once the leading-edge BL transition was fixed, a series of runs was conducted to determine the effect of slot height variation. Details in Figure 16 show lift variation with blowing at $\alpha=0^{\circ}$ for a family of nominal slot heights (not yet corrected for expansion due to pressure). 2-D $\mathrm{C}_{1}$ values of $8-9$ were recorded. Figure 17 summarizes the trend in lift variation with slot height at a typical $C \mu=0.3$, where the nominal slot heights have been corrected to their 


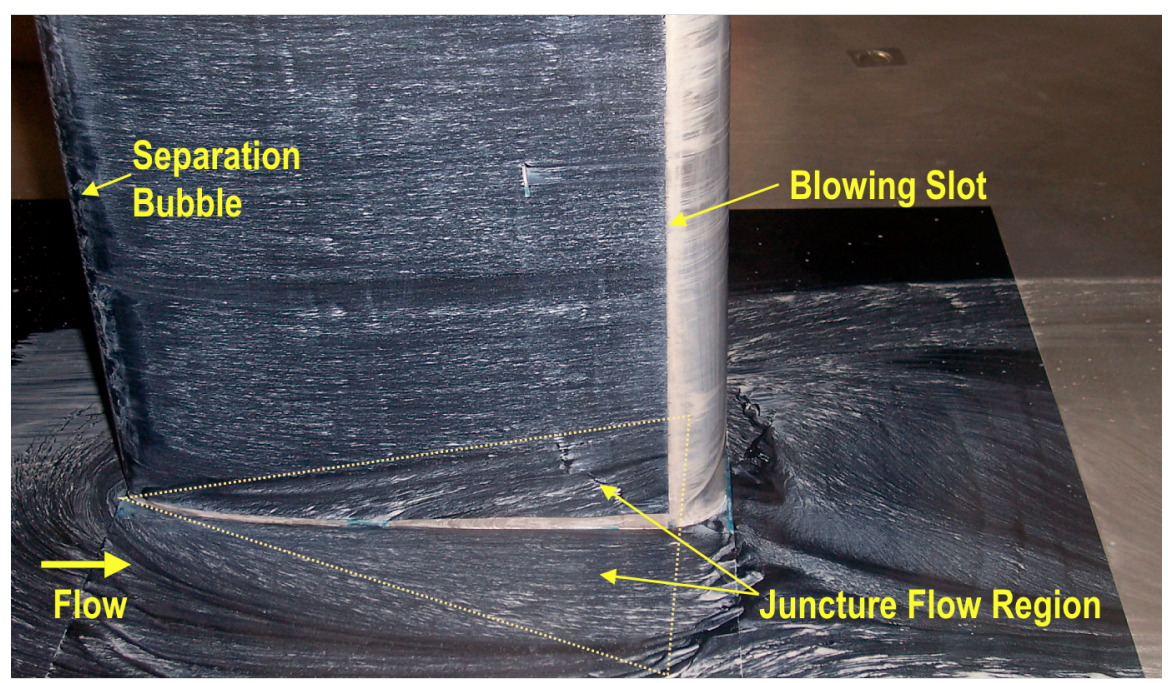

Figure 14- Oil flow visualization on the model upper surface, $\mathrm{C} \mu=0.3$

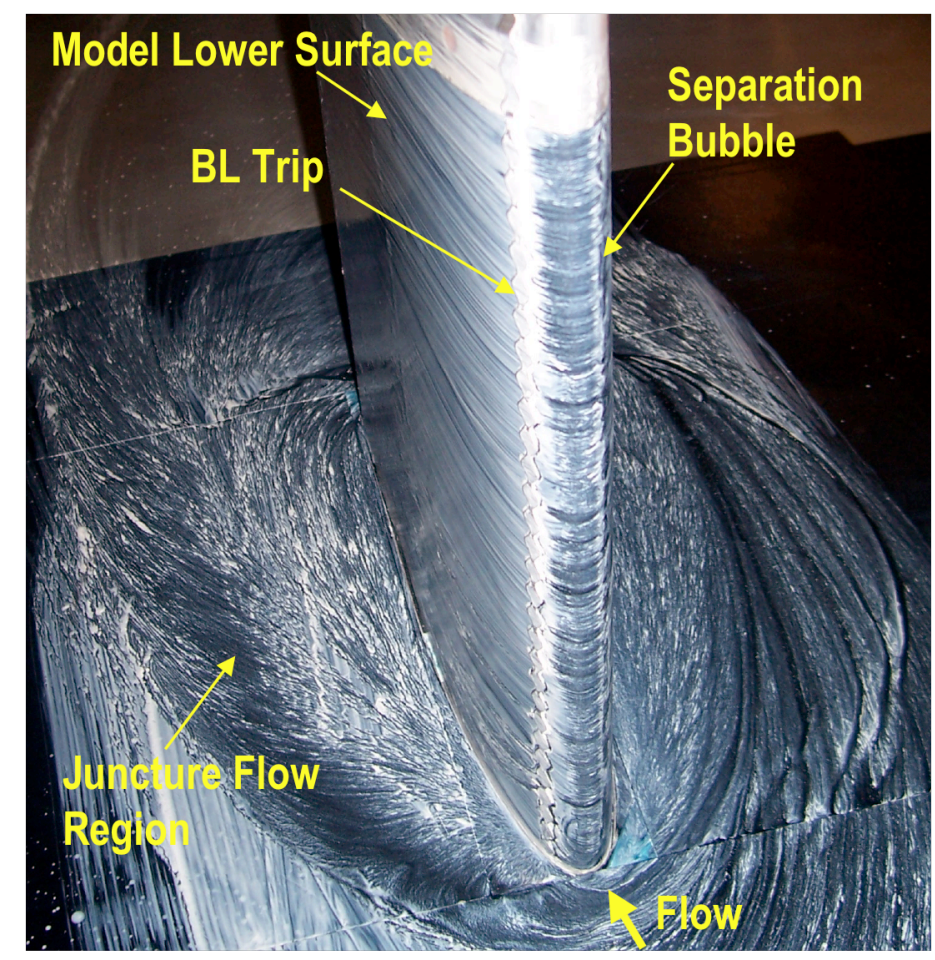

Figure 15- Oil flow visualization on the model lower surface near its leading edge, $\mathrm{C} \mu=0.3$.

actual expanded values due to internal pressure. Both figures confirm the very high lifting capacity available from tangential blowing rather than angle of attack, and the importance of such pneumatic parameters as blowing slot height. There appears to be a range of intermediate slot heights for maximum lift performance at a fixed $\mathrm{C} \mu$. Since past experience (Refs. 1 and 2 for example) had implied greater performance for smaller slot heights at a fixed $\mathrm{C} \mu$, further understanding of slot effect is still needed. Part of this is investigated in the CFD discussion below. 


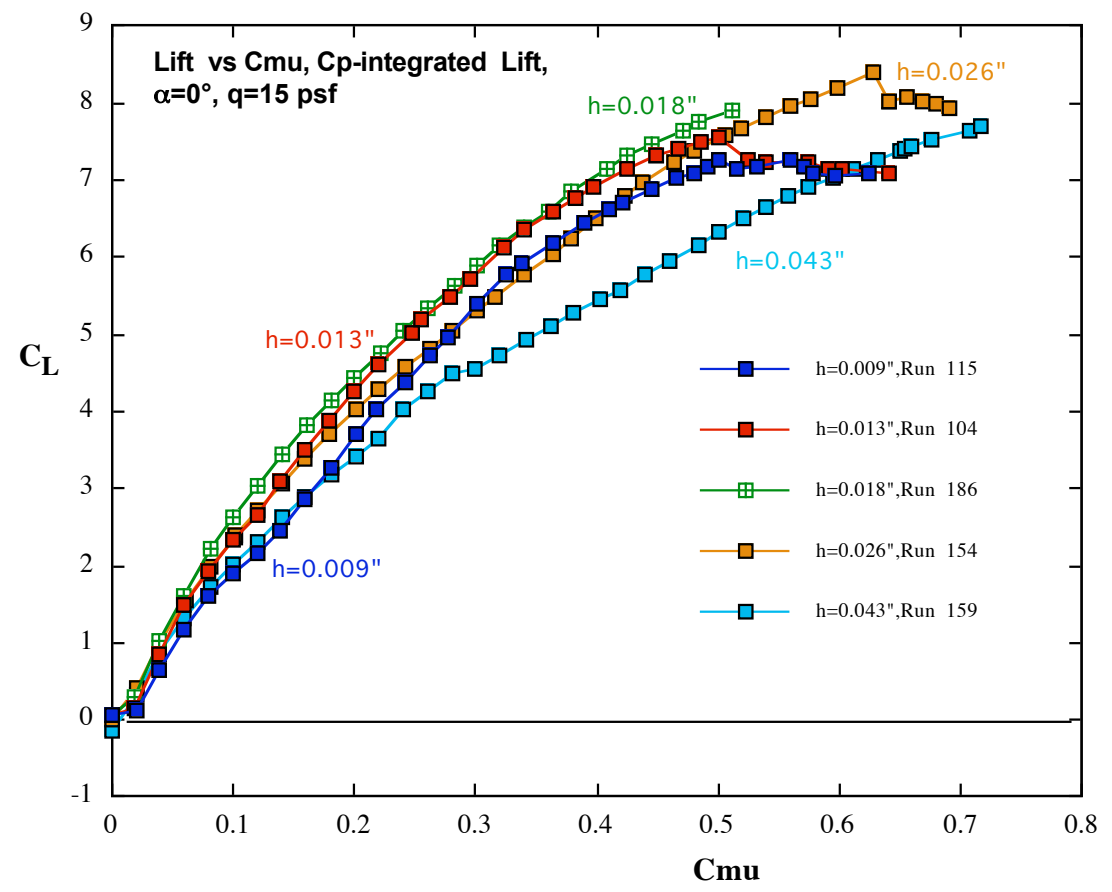

Fig. 16 - Lift Generated by Blowing and Various Nominal Slot Heights at $\alpha=0^{\circ}$

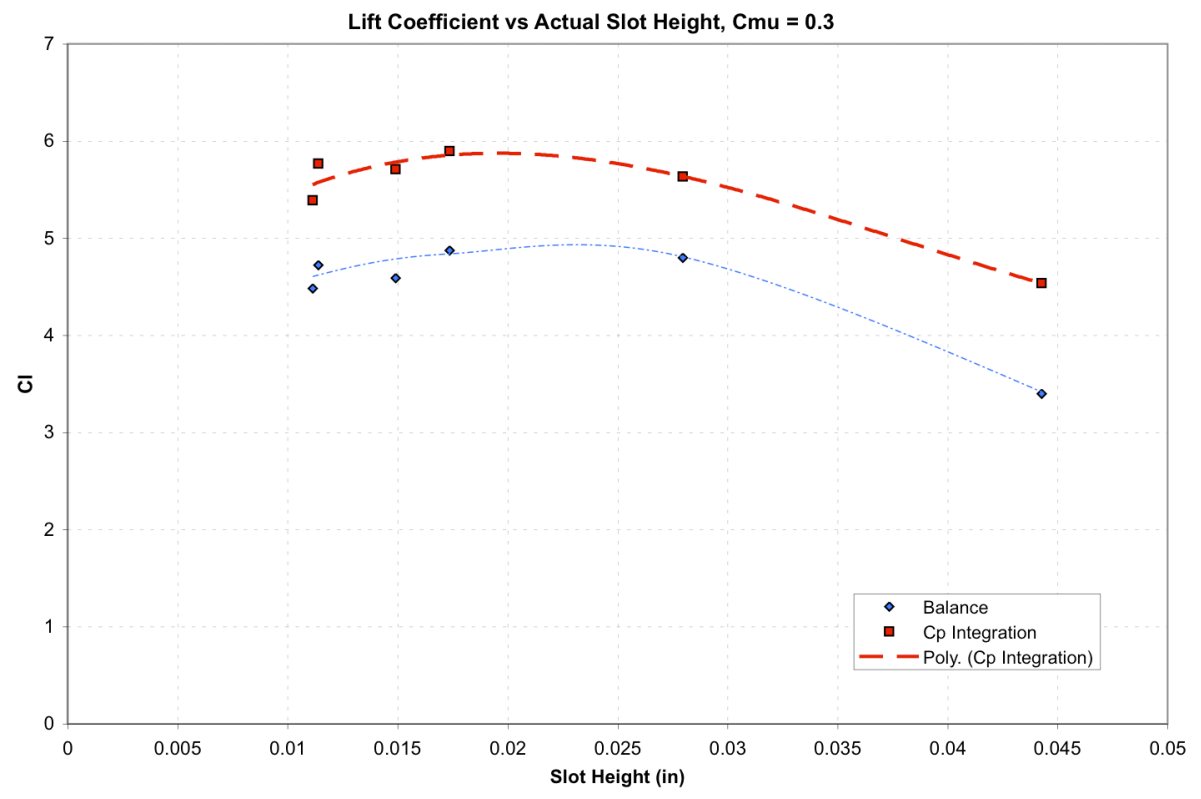

Fig. 17- Lift Generated by Blowing and Varying Effective Slot Heights at $\alpha=0^{\circ}$ and $\mathrm{C} \mu=0.30$

There is also noted a strong effect of leading-edge flow attachment in these high-lift results. Figures 12, 13, and 15 discussed this from a standpoint of possible laminar flow bubble formation, and Figure 18 shows leading-edge stall and a locus of stall points varying with $\mathrm{C} \mu$ at very high super-circulation due to blowing and $\alpha$ at a constant $h=0.009$ " slot height. Fig. 19 shows similar alpha-stall loci for several slot heights. The basic airfoil can even stall at negative values of angle of attack once the blowing increases to the point where even the bluff elliptic 
nose radius can't maintain flow attachment there at very high streamline inflow angle. A change in aft slot heights, h, in Fig. 19 has relatively little effect. It is for this reason that a more effective leading-edge device, probably in the form of tangential blowing, will need to be considered in future studies of these types of high-lift airfoils. The second year of the current NASA effort has already yielded a modification to the current model where a leading edge tangential slot had been installed. Testing at both GTRI and NASA will confirm its effectiveness.

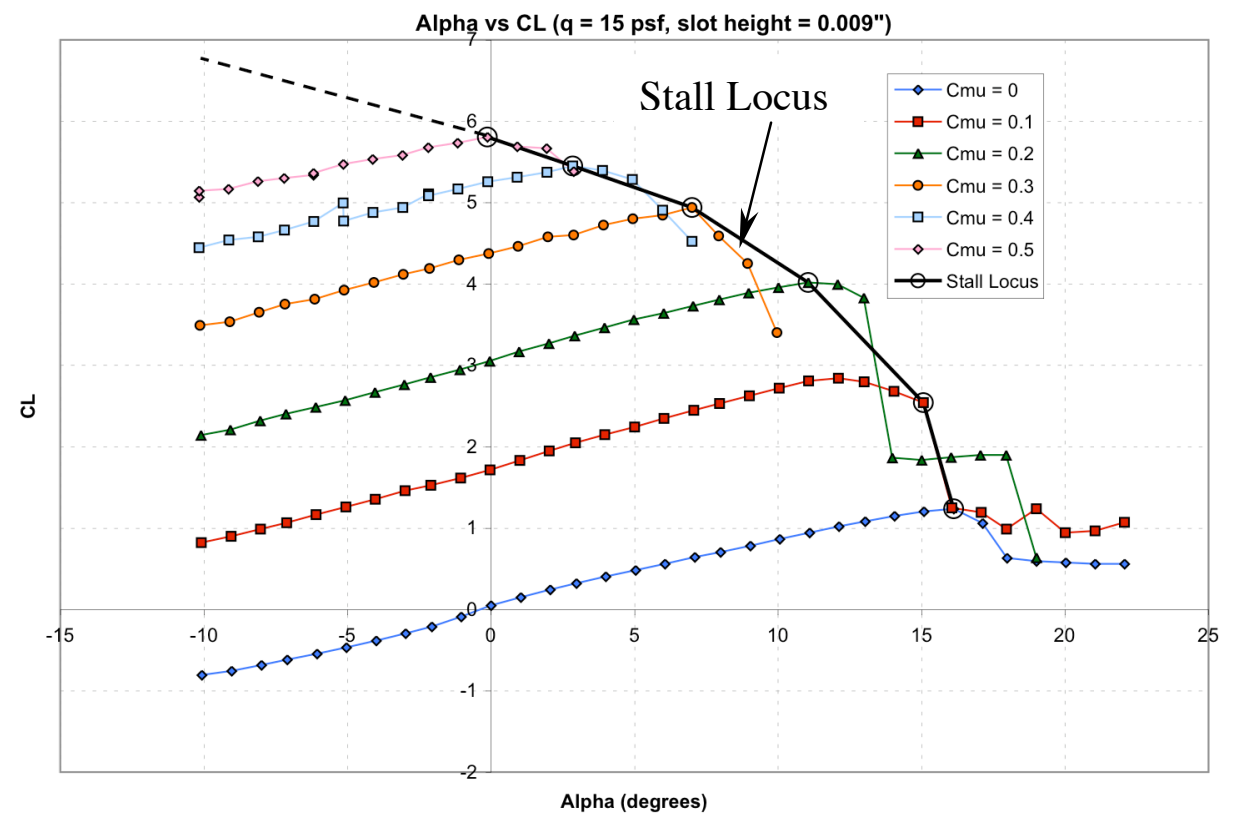

Figure 18- Lift variations with $\alpha$ at $\mathrm{h}=0.009$ " and constant $\mathrm{C} \mu$.

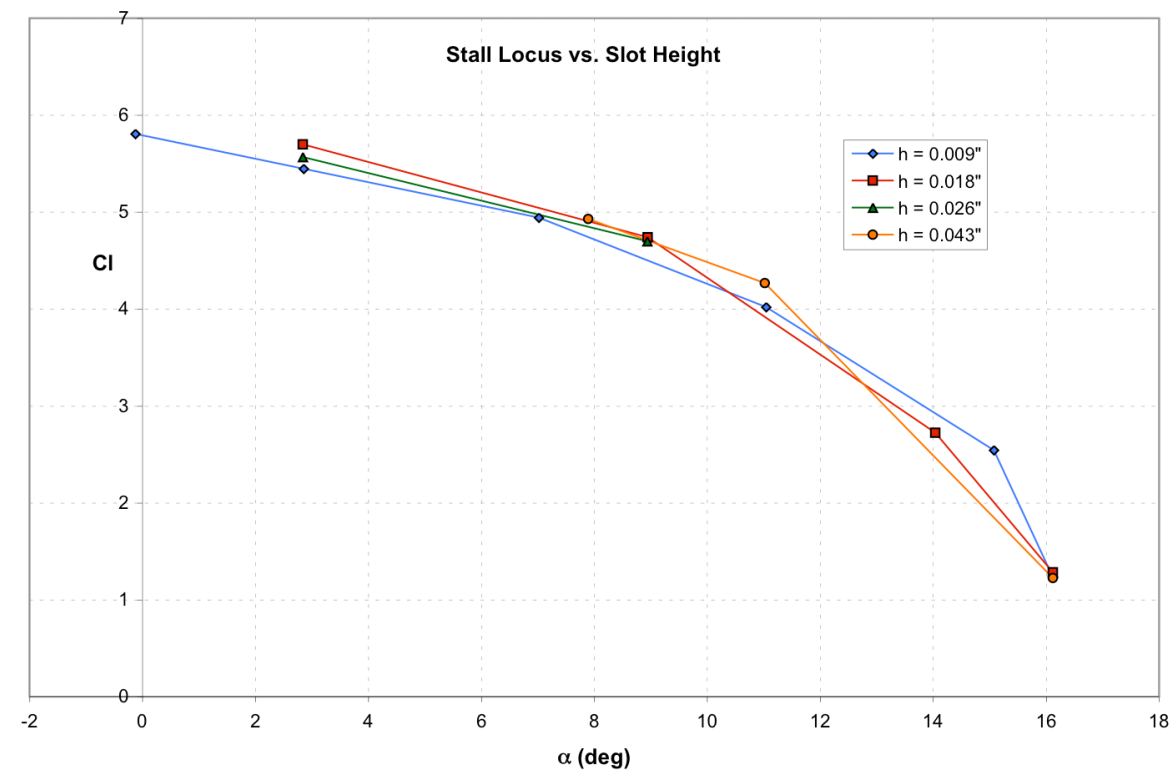

Figure 19- $C_{1}-\alpha$ stall loci at constant $C \mu$ and nominal slot height 
Additional force and moment data taken at GTRI reveal further aerodynamic characteristics of this blown airfoil. Figure 20 shows increased lift augmentation from blowing at $\alpha=0^{\circ}$. This represents the return on investment of $\mathrm{C} \mu$ input, probably obtained from the aircraft engines or an onboard APU. Values as high as 26 or more are seen, with the highest values coming from intermediate slot heights. Figure 21 shows nose-down quarter-chord pitching moment associated with the suction spikes just aft of the upper slot location. It is obvious that additional trim capability may be needed; this could be provided with either leading-edge blowing of blowing out of the lower slot (Fig. 1). Drag produced by blowing at $\alpha=0^{\circ}$ is presented in Figure 22. It should be noted that this is balance-determined drag coefficient. In many of the wake-rake drag measurements, the momentum deficit was found to extend beyond the end of the 72-probe rake itself, thus invalidating that data, and so only the balance data were available. It is noticed that drag varies considerably with slot height and with blowing, but for each slot height, there appears to be a minimum $C_{d}$ value around $C \mu=0.03$ to 0.06 . Then drag increases with blowing. Figure 23 presents an equivalent lift-to-drag ratio for these same cases. Here, an attempt is made to account for the $C \mu$ expended by using $L / D_{\text {eq }}=C_{1} /\left(C_{d}+C \mu\right)$; see Ref. 5 for further discussion. Thus the most efficient configuration is found to be the intermediate slot height $(\mathrm{h}=0.018$ ") in the $\mathrm{C}_{1}$ range of 1.5 to 2.5. Again, it is reminded that these thick bluff generic airfoils will not be characteristic of a typical pneumatic CC airfoil's cruise-efficient performance.

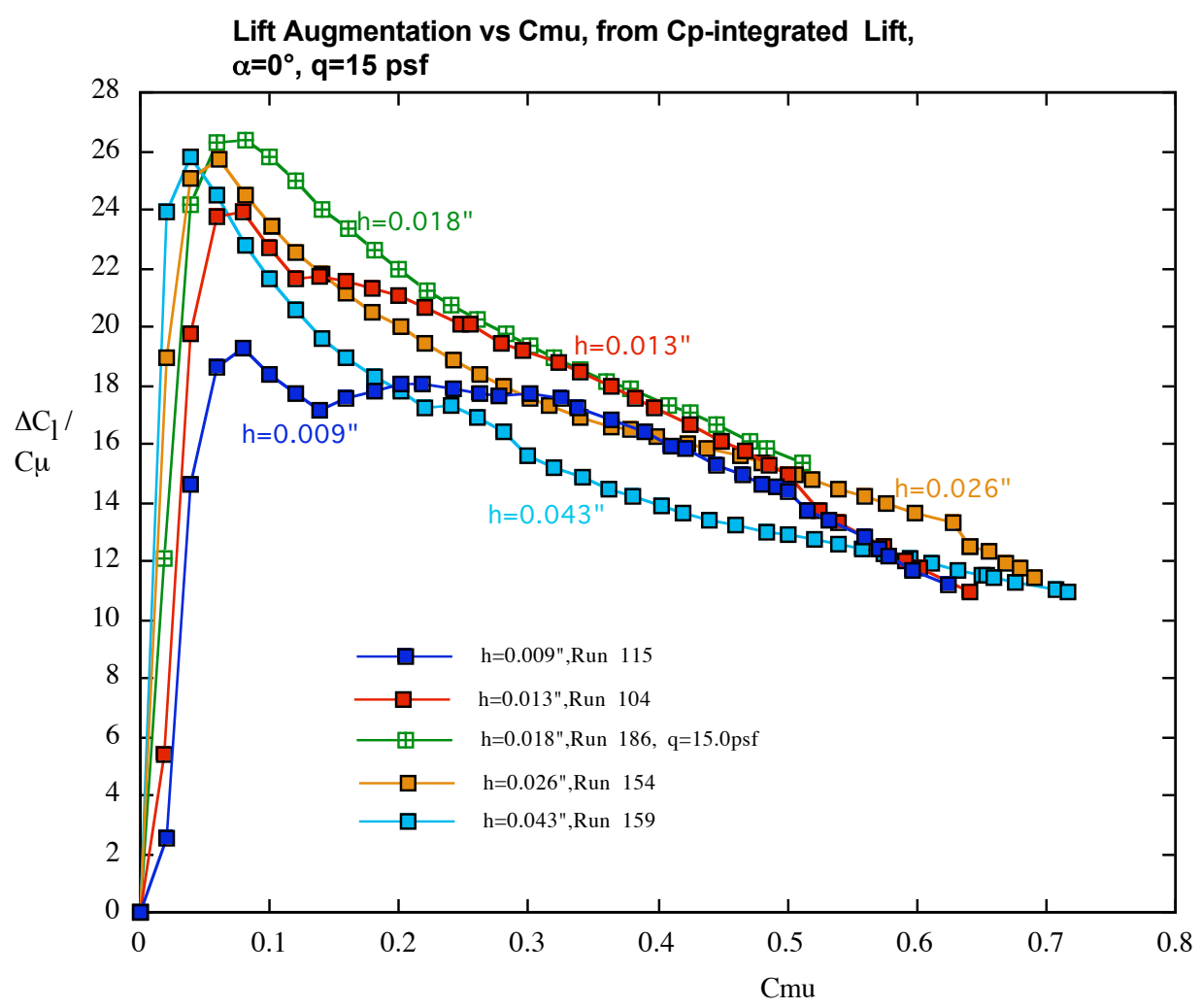

Figure 20- Lift augmentation with $\mathrm{C} \mu$ at $\alpha=0^{\circ}$ 


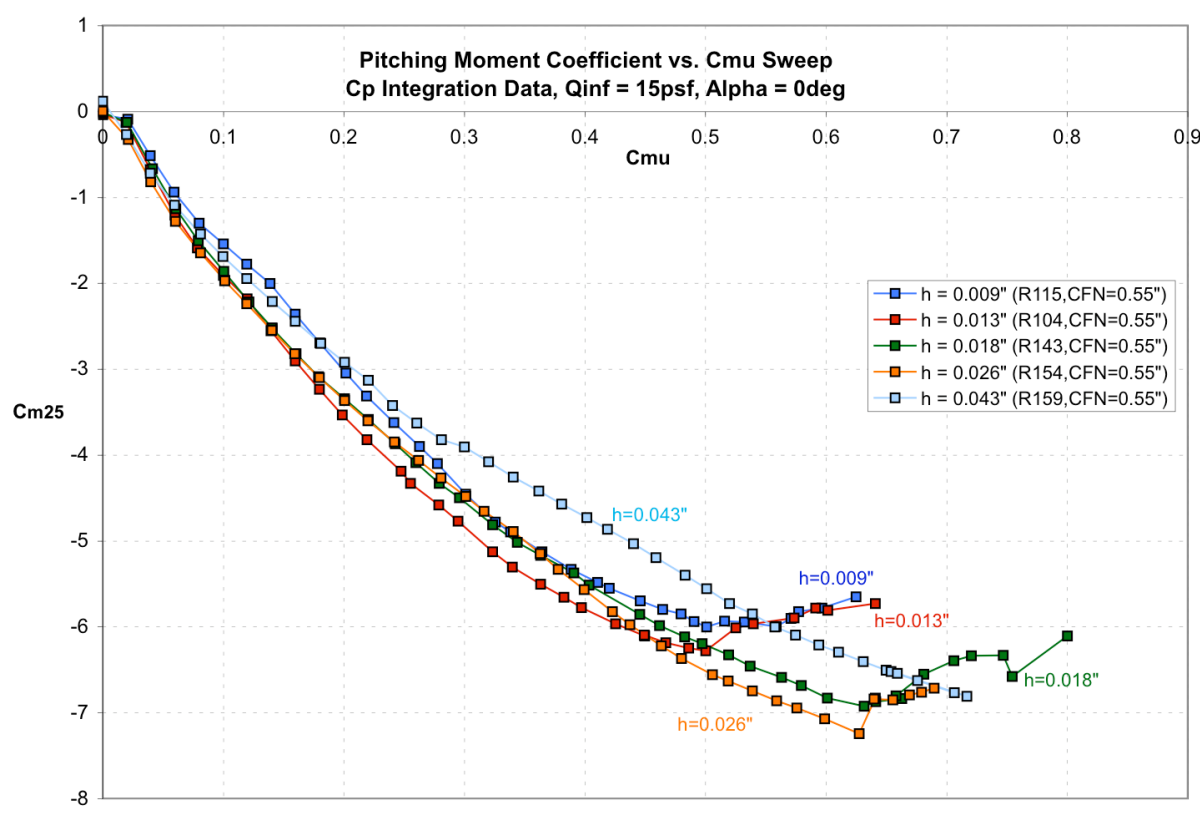

Figure 21- Pitching moment variation with $C \mu$ at $\alpha=0^{\circ}$

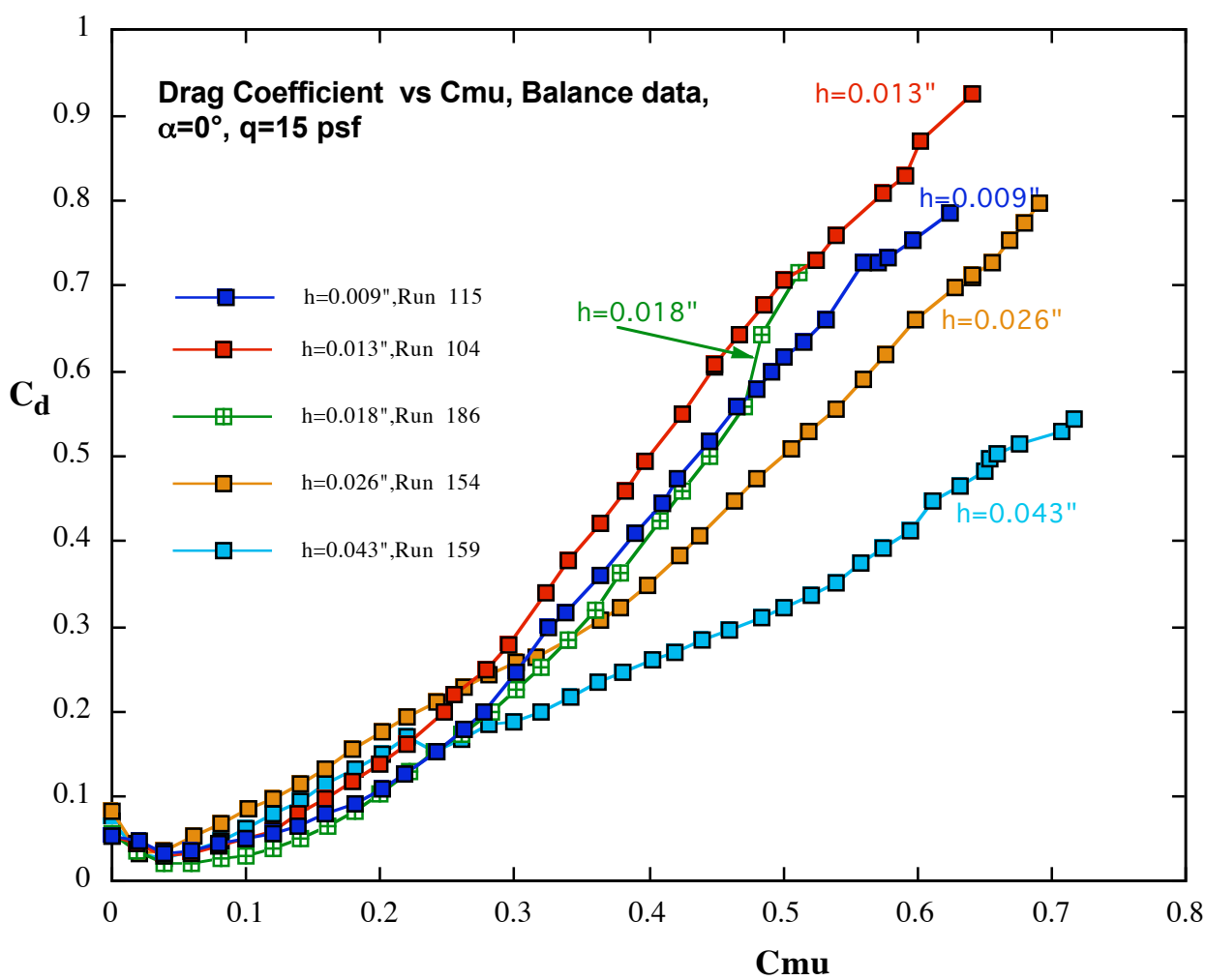

Figure 22- Drag Variation with $\mathrm{C} \mu$ at $\alpha=0^{\circ}$ 


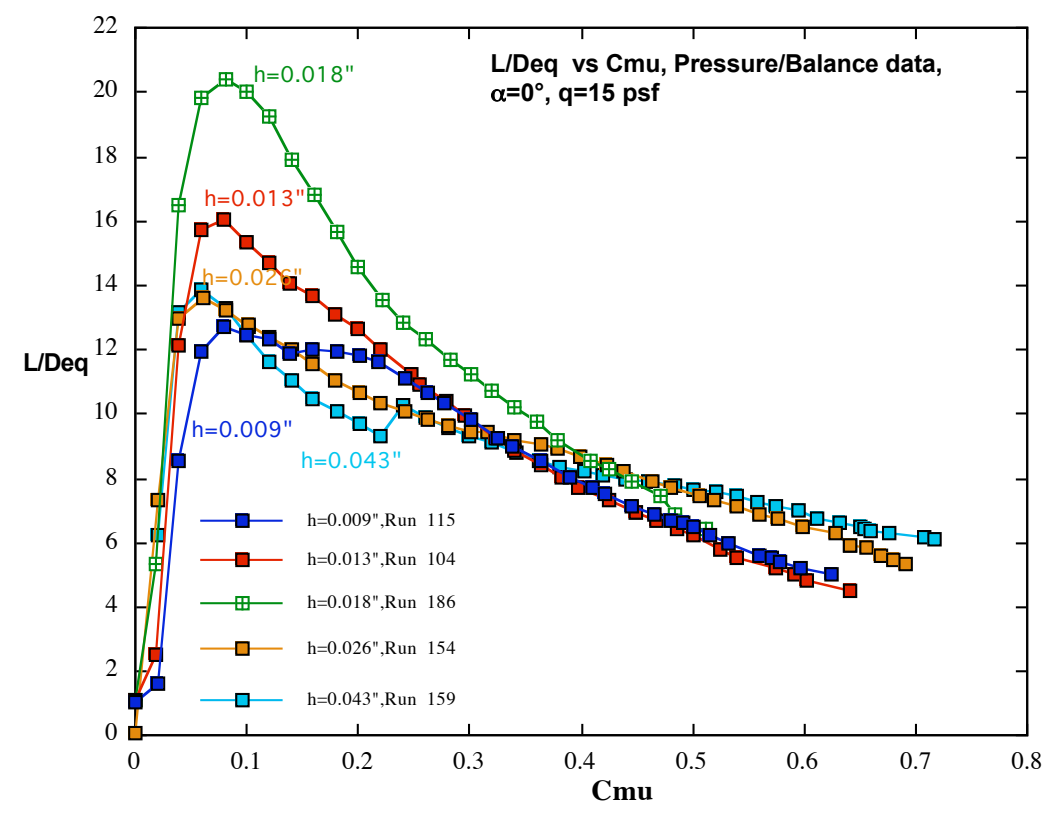

Figure 23- Equivalent Lift-Drag ratio with $C \mu$ at $\alpha=0^{\circ}$

\section{2-D Experimental Results, Blowing ON, NASA BART}

After the initial evaluations at GTRI above, the test 2-D CC airfoil was transferred to NASA LaRC for additional experimental testing, primarily to evaluate more specific flow characteristics, which would aid in the CFD boundary conditions and flow field details. The BART installation is shown in Figure 24, where again a force balance and pressure recording instrumentation are available. Flow visualization was discussed above. Hot wire investigations were conducted to evaluate the jet initial conditions.
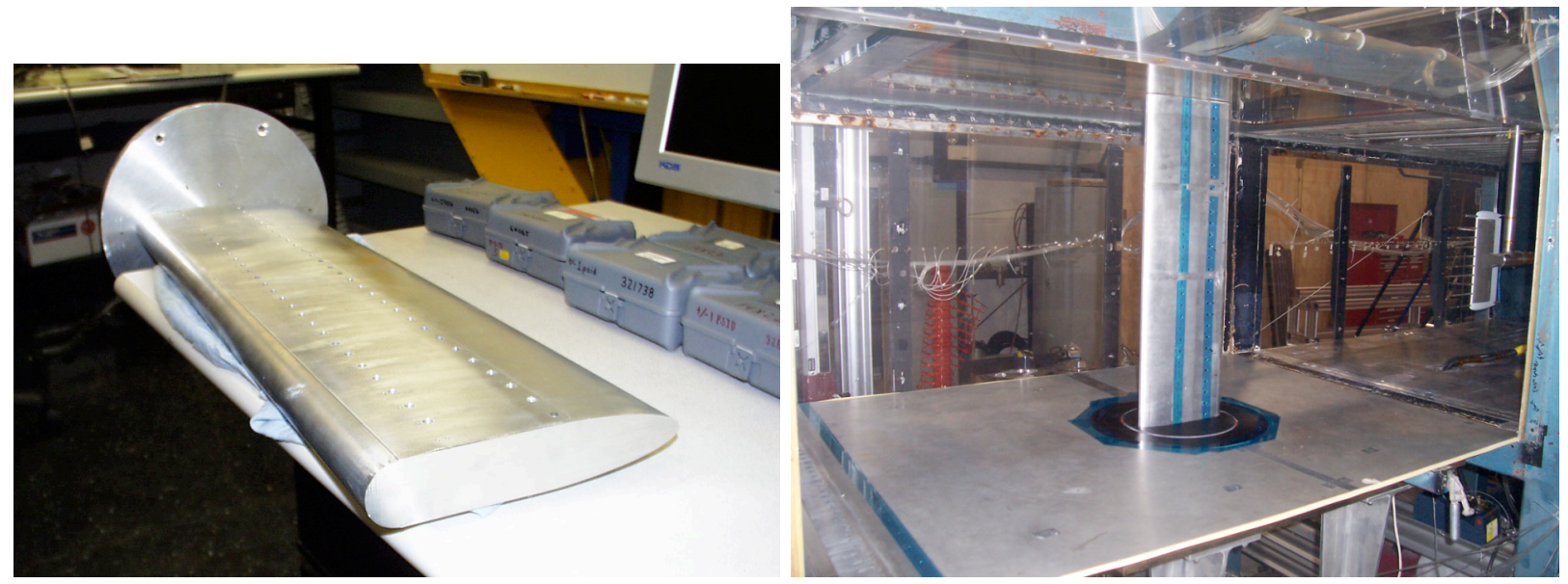

Figure 24- CC Airfoil and installation in the NASA BART tunnel (28"span)

The jet-exit velocity used to calculate the momentum coefficient is a critical boundary condition for CFD. Attempts to measure the jet profile during the wind tunnel phase of the test were complicated by the relative size of the probe with respect to the slot height $(\mathrm{h})$. The small slot height limited the available measurement techniques to hot-wire probes and custom pitotprobes. Optical methods such as PIV were not attempted due to seeding and spatial resolution 
issues. Model movement and probe vibration along with probe alignment increased the measurement uncertainty to levels that were undesirable for slot heights less than 0.050 inches. Therefore, the jet profile was measured in a controlled bench top environment. It is assumed that the jet-exit profile is only influenced by the outer flow through the expansion of the jet to freestream static pressure. The variation of the open return tunnel to the bench top static pressure is minimal.

Figure 25 shows the jet-exit profile with no external flow and highlights the influence of applying hot-wire calibrations obtained at different reference temperatures. Matching the calibration temperature and the jet total temperature results in an approximate $1.5 \%$ overshoot of the maximum jet velocity when compared to the velocity obtained from the pressure ratio $\left(U_{\text {Pratio }}\right)$. Based on these results, all of the jet profiles obtained using a hot wire were temperature corrected to the jet total temperature.

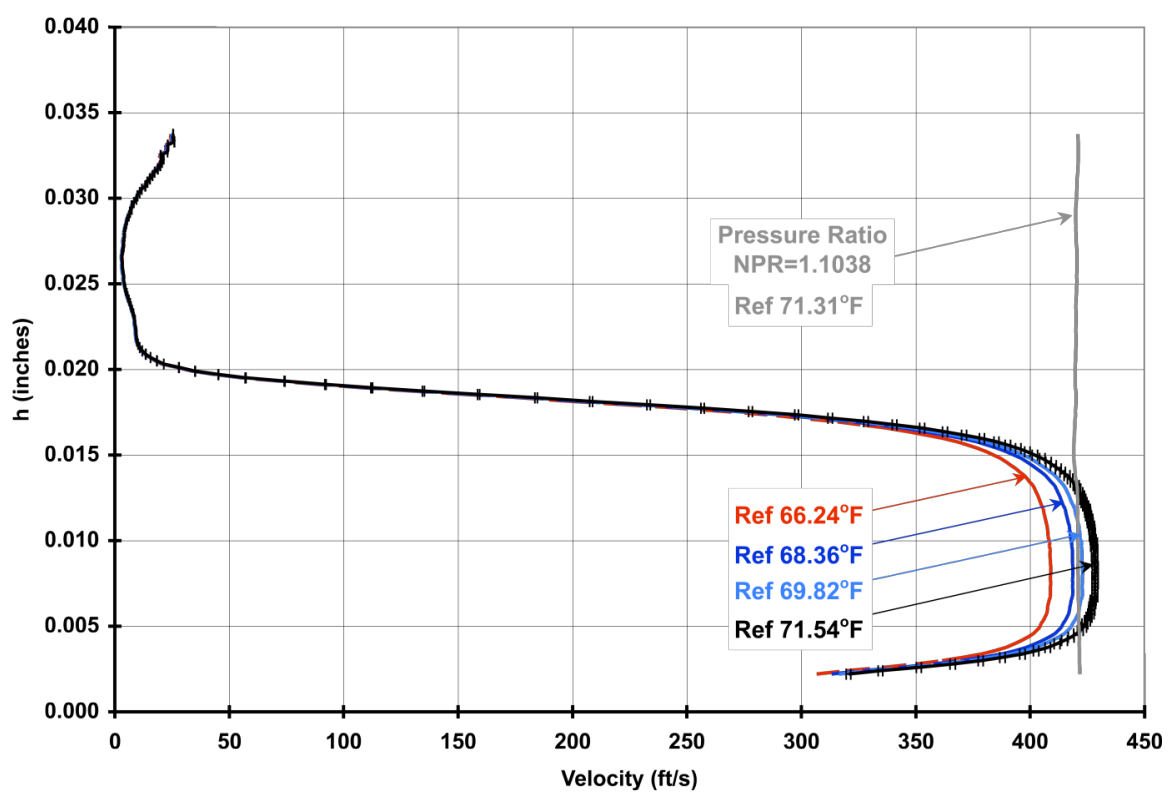

Figure 25- Hot-wire mean-velocity profile at jet exit using different calibration temperatures, $z / Z_{\mathrm{REF}}=0.75$, $\mathrm{U}_{\text {Pratio }}=420 \mathrm{ft} / \mathrm{sec}$. The velocity uncertainty is shown for a reference temperature of $71.5^{\circ} \mathrm{F}$.

The largest uncertainty in the hot-wire measurements is associated with zeroing the position of the probe relative to the model surface at the jet exit. The sensor is assumed to be located at the center of the prong tips. The tips are typically taken to the model surface, then stepped off of the surface until the turbulence signal becomes stable. The turbulence profile shown in Figure 26 is used to characterize the slot height. The flapping motion of the shear layer at the jet exit peaks at 0.01794 inches. This is consistent with the optical measurement technique used to identify the movement of the skin at the jet exit. 


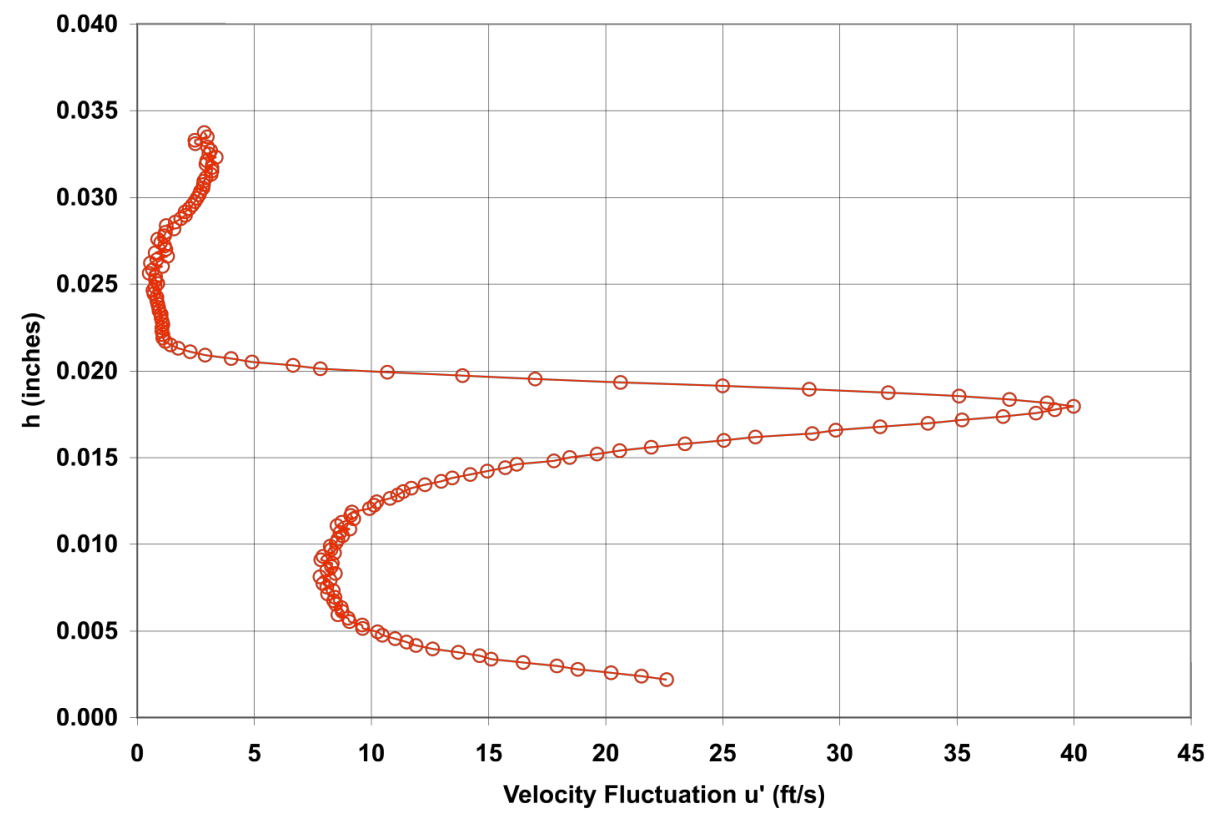

Figure 26- Hot-wire turbulence profile at jet exit, $\mathrm{z} / \mathrm{Z}_{\mathrm{REF}}=0.75, \mathrm{NPR}=1.1038, \mathrm{To}=71.3^{\circ} \mathrm{F}$

Experimental lift from both force balance and integrated $\mathrm{Cp}$ distributions are shown for the two test facilities in Figure 27. The integrated $\mathrm{Cp}$ results agree fairly well, but unlike the GTRI results, the NASA data shown little difference between balance-recorded and Cp-derived lift, implying two possibilities. The effects of the NASA floor blowing systems to retain 2-D lift conditions may be somewhat less than at GTRI. A second possibility is that the NASA Cp data

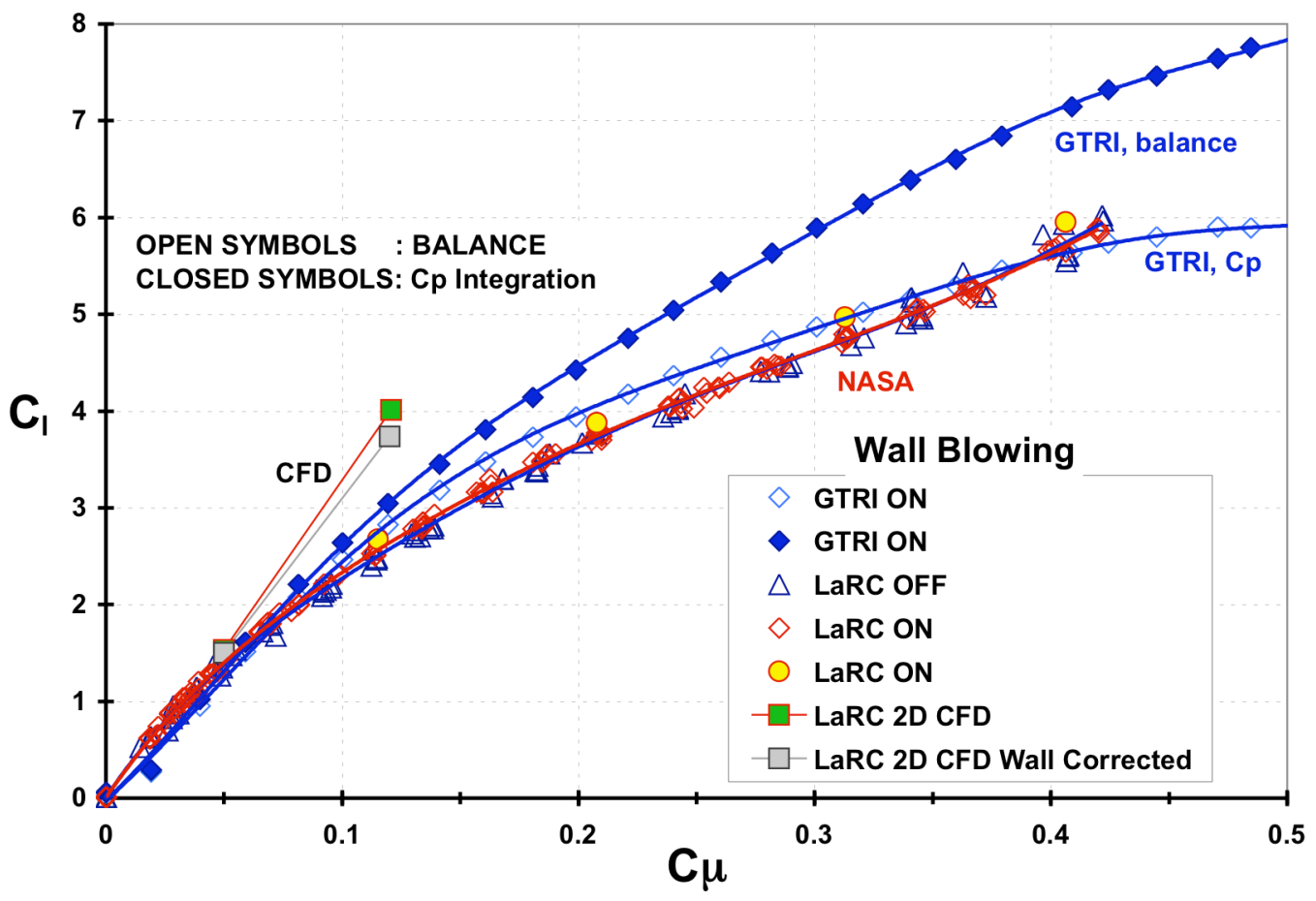

Figure 27- Lift results comparison: MTF and BART; $\alpha=0^{\circ}$ 
does not include the very high suction spike just downstream of the blowing slot (see Figure 12), and thus the lift increment due to it is not included in $\mathrm{C}_{1}$. To address this possibility, the next set of tunnel tests will have several additional static taps installed in that region to verify if that suction reading is internal or external to the slot exit for the lift calculation, and thus should not or should be added. A further interesting point from Figure 27 is that two sets of CFD data (see discussions below) are included, and both overpredict any of the measured lift by a considerable. amount. This is not unusual, due frequently to the applied turbulence model in the jet (see Refs. 3 and 6).

A further comparison in terms of drag data is seen in Figure 28. Here, in two cases of NASA data, the floor blowing produces lower drag at a given $\mathrm{C} \mu$ than floor blowing off. NASA drag data is seen to be slightly less than that of GTRI, but both sets show similar trends. Thus the two separate experimental undertakings seem to have produced representative data that can be used to validate results from CFD efforts. Those will be addressed briefly next.

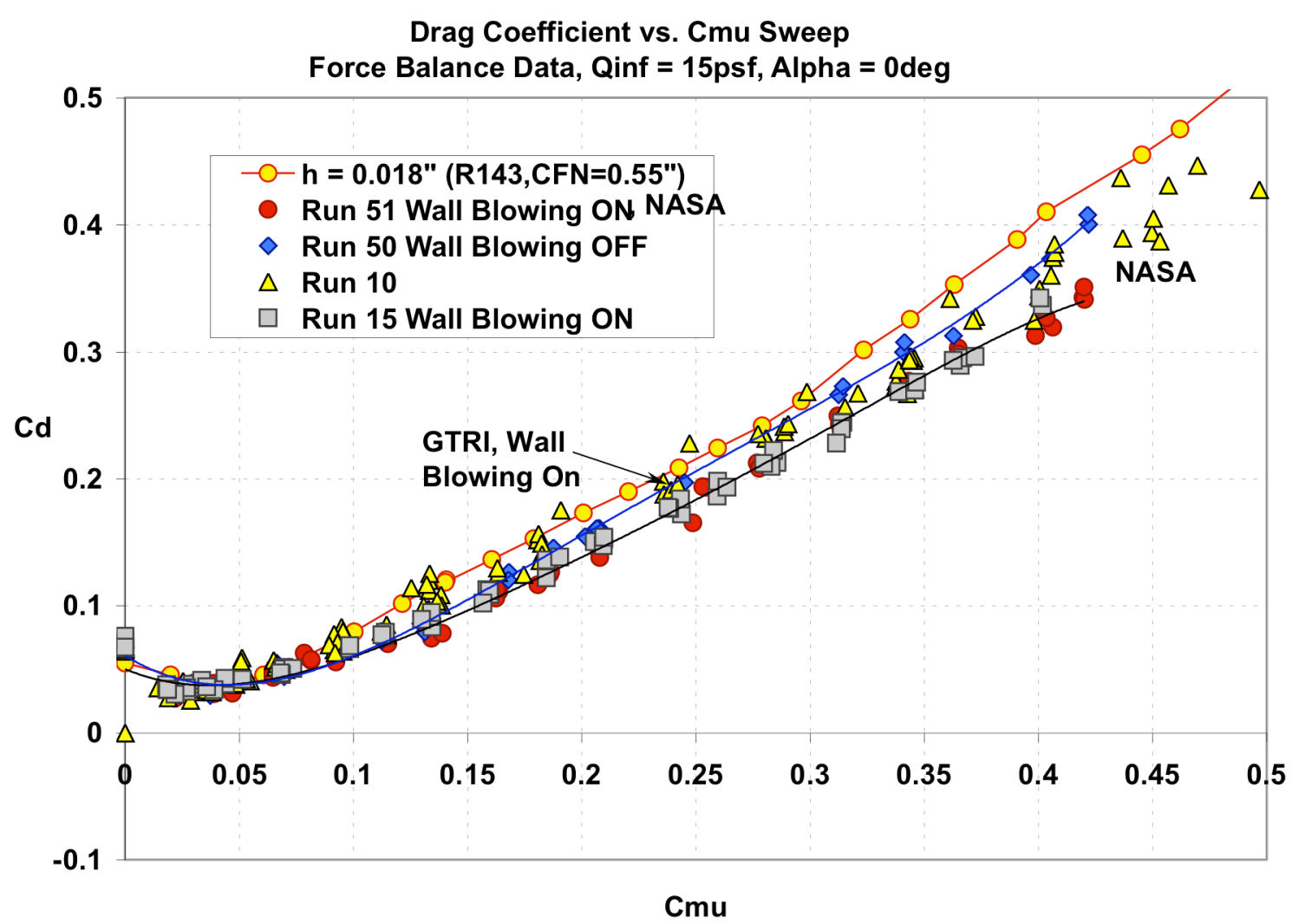

Figure 28- Wall blowing effects on drag from balance, $a=0^{\circ}$

\section{CFD Validation, Numerical Simulations}

\section{Flow Solver}

Whereas the experimental data were intended to assist in the validation of the CFD codes to be used for future $\mathrm{CC}$ airfoil performance, the CFD calculations were also used as a guide for evaluating tunnel two-dimensionality and wall interference. Since both are related to the quality of the baseline data, the CFD results will be considered in this paper as well. 
Numerical simulations were performed using the flow solver code, OVERFLOW ${ }^{7,8}$ developed at NASA. This code solves the compressible Reynolds-averaged Navier-Stokes (RANS) equations using the diagonal scheme of Pulliam and Chaussee ${ }^{9}$. The RANS equations are solved on structured grids using the overset grid framework of Steger, Dougherty, and Benek. ${ }^{10}$ This overset grid framework allows for the use of structured grids for problems that have complex geometries and moving bodies. The numerical simulations were performed using the parallel version of the OVERFLOW code developed by Buning. ${ }^{11}$ This code uses the Message-Passing Interface and can run on a tightly-coupled parallel machine or a network of workstations. The code distributes zones to individual processors and can split larger individual zones across multiple processors using a domain decomposition approach. Turbulence was modeled using Menter's Shear Stress Transport (SST) model. ${ }^{12}$

\section{Grids}

Figure 29 shows the overset grids used for the Circulation Control airfoil simulations generated using the Chimera Grid Tools software developed at NASA. ${ }^{13}$ The 2-D simulations had 59 overset structured grids with 11 near body grids and 48 grids off-body cartesian grids with isotropic grid spacing. The simulation had approximately 500,000 grid points with 300,000 point for the near body grids and 200,000 for the off-body meshes generated automatically by the OVERFLOW code. There are a total of 1,242 points around the airfoil with 401 points concentrated on the Coanda trailing edge surface. The internal plenum geometry was modeled including part of the first chamber geometry. The internal geometry was modeled to accurately model the internal flow in a 2-D sense and to improve our understanding of the internal flow. In the actual model the internal flow for the first plenum starts from the wing root and travels down the model to the wing tip resulting in a 3-D flow component not modeled in the 2-D simulations. The initial wall spacing for the near body grids was adjusted in order to achieve a $y+$ spacing less than or equal to one.

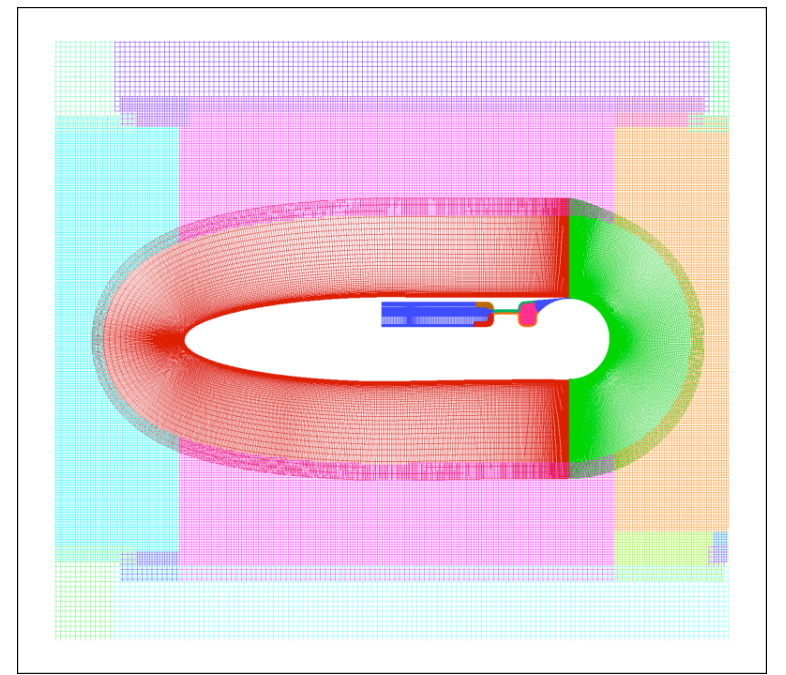

a)

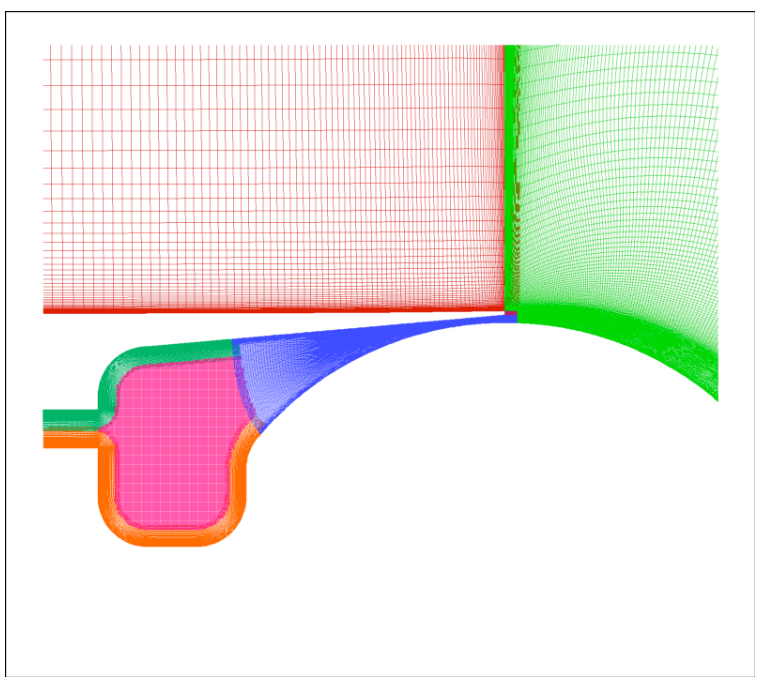

b)

Figure 29. a) Overset grids for circulation control airfoil with b) a close-up view of the internal nozzle geometry at the slot exit. 
The comparisons of CFD to experiments require a critical evaluation of the twodimensionality and blowing conditions of the experiments. Preliminary evaluations utilized CFD to estimate the influence of the wind-tunnel wall effects on jet exit conditions, model angle of attack, and free stream dynamic pressure. Figure 30 illustrates the wall juncture flow that is consistent with the BART aspect ratio of 3.26. The remainder of this text will emphasize 2-D evaluations.

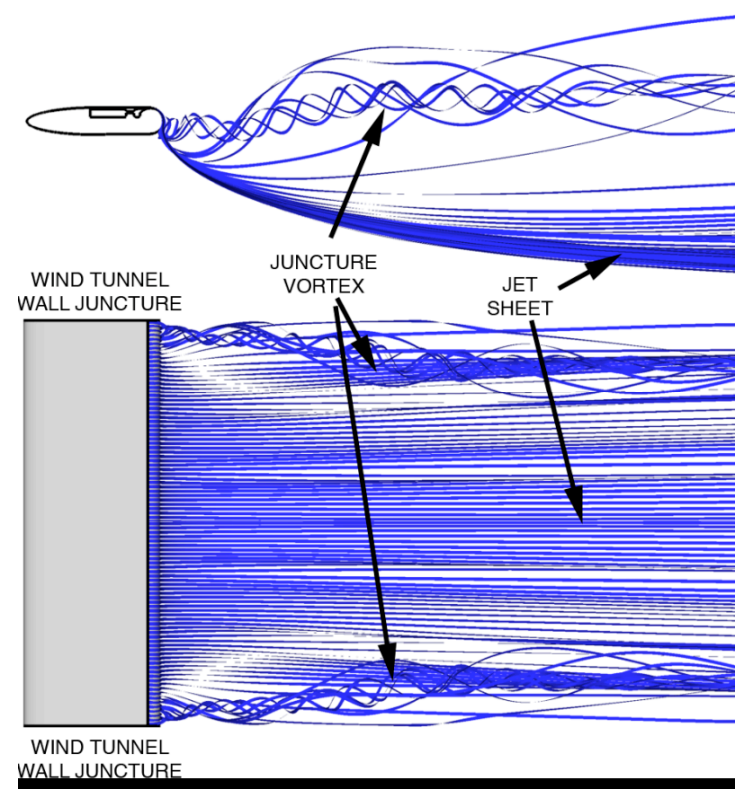

Figure 30- CFD wall juncture flow simulation

\section{Estimated Wall Corrections}

Figure 31 and 32 show the experimental surface pressure measurements acquired at the NASA BART tunnel compared to the 2-D CFD calculations. The jet boundary conditions for the simulations are defined by setting the total pressure and total temperature at the inflow boundary on the first plenum chamber. Figure 31a shows the surface pressures for a 2-D CFD simulation that matches the experiment at an NPR of 1.208 and a C $\mu$ of 0.115. In this comparison, the CFD is showing a suction peak downstream of the slot much larger than the negative pressure measured in the experiment. [Note however that this suction peak was recorded in the GTRI data, such as Figure 12] This difference is thought to be related to the turbulence modeling of the wall jet as discussed by Swanson et al. ${ }^{14}$ This large suction peak results in an over prediction of the coefficient of lift by the CFD for the same slot blowing conditions as the experiment.

A secondary effect that results in the 2-D CFD having a larger lift than the experiment is the influence of the wind tunnel end walls. In the experiment the juncture flows result in a downwash on the model reducing the effective angle-of-attack of the model in the wind tunnel. This end-wall influence can be accounted for by using an angle-of-attack correction for the 2-D CFD simulations. Wall corrections from the experimental data are being pursued and are currently unavailable for the recent wind tunnel data. Therefore an estimate of the wind tunnel angle-of-attack correction was made using a CFD approach. 


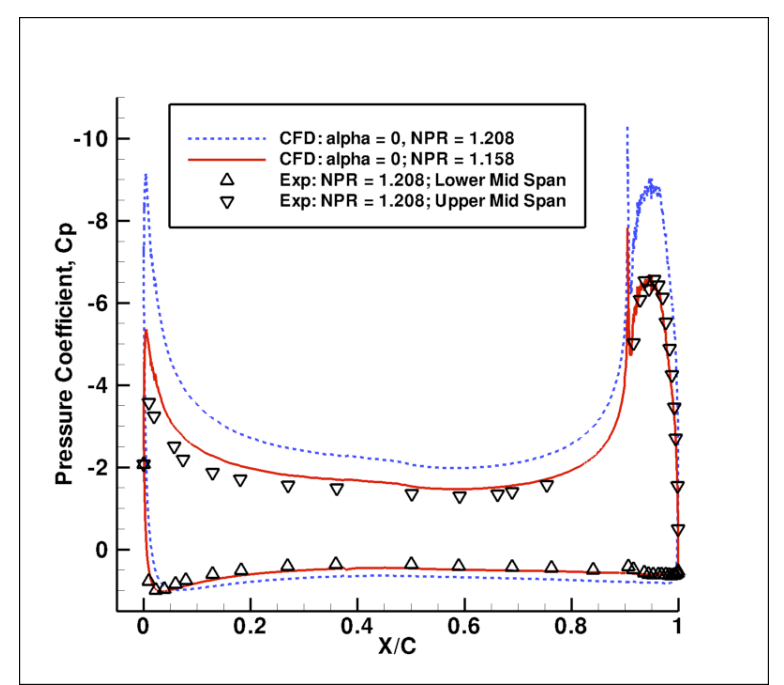

a)

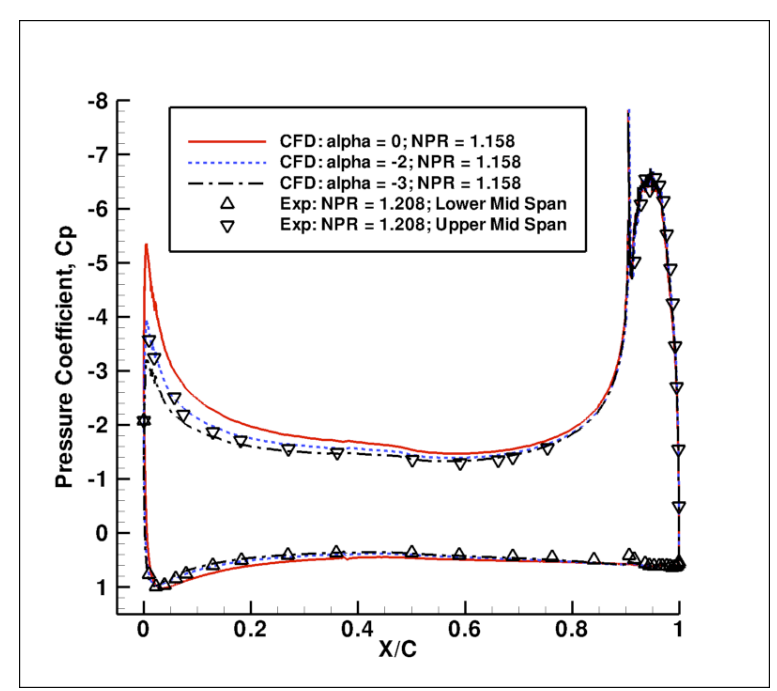

b)

Figure 31- Surface pressures for CFD and experiment a) showing adjustment of CFD jet boundary condition to match experimental pressures at the trailing edge and b) angle-of-attack adjustments to match pressures at the leading edge of the airfoil for the $C \mu=0.10$ case.

Estimates of the wall correction are made by first adjusting the jet NPR boundary conditions in the CFD simulation to match the measured peak surface pressures downstream of the slot. Figure 31a shows that by reducing the CFD jet NPR to a value of 1.158 , the peak suction pressure from the CFD now matches the experimental data. The idea is that by adjusting the jet NPR to match the experimental surface pressures, the CFD is now simulating the effects of the jet at the trailing edge for the purpose of this wall correction estimate. Figure 31a shows that by reducing the NPR to 1.158, the suction peak has also been reduced on the leading edge of the airfoil, but it is still higher than the experiment. To obtain the angle-of-attack wall correction, the airfoil in the CFD simulation is pitched until the peak suction pressure at the leading edge matches the experimentally measure values. Figure $31 \mathrm{~b}$ shows the surface pressure for three different angles-of-attack from the 2-D CFD where the peak pressure at the leading edge of the airfoil matches the experiment when pitched to $\alpha=-2.0$ degrees. Thus from this comparison, an estimated wall correction using the CFD is -2.0 degrees for the $C \mu=0.115$ blowing case tested at the BART tunnel. The same approach was also performed for the $\mathrm{C} \mu=0.047$ blowing case as that shown in Fig. 31, and resulted in an estimated wall correction of -0.9 degrees. A summary of the CFD simulations and experimental data is given in Table I, showing a comparison of the mass flow rates and coefficients of lift and drag. 
Table I. Summary of CFD and experiment for Circulation Control airfoil at two blowing conditions.

\begin{tabular}{|c|c|c|c|c|c|c|c|c|}
\cline { 2 - 9 } \multicolumn{1}{c|}{} & NPR & $\begin{array}{c}\text { Estimated Angle- } \\
\text { of-Attack } \\
\text { Wall Correction } \\
\text { (deg) }\end{array}$ & $\begin{array}{c}\text { Mdot } \\
\text { (lbm/s } \\
\text { per ft span) }\end{array}$ & $\begin{array}{c}\mathbf{C} \boldsymbol{\mu} \\
\text { (Integrated) }\end{array}$ & $\begin{array}{c}\mathbf{C}_{\boldsymbol{\mu}} \\
\text { (Isentropic) }\end{array}$ & $\mathbf{C}_{\mathbf{L}}$ & $\begin{array}{c}\mathbf{C}_{\mathbf{L}} \\
\text { (Balance) }\end{array}$ & $\mathbf{C}_{\mathbf{D}}$ \\
\hline Exp & 1.081 & N/A & 0.0442 & & 0.047 & 1.363 & 1.311 & 0.0312 \\
\hline CFD & 1.081 & 0.0 & 0.0442 & 0.050 & & 1.533 & & 0.0367 \\
\hline CFD & 1.075 & 0.0 & 0.0425 & 0.0463 & & 1.541 & & 0.0373 \\
\hline CFD & 1.075 & -0.9 & 0.0423 & 0.0460 & & 1.414 & & 0.0369 \\
\hline Exp & 1.208 & N/A & 0.0701 & & 0.115 & 2.711 & 2.757 & 0.0701 \\
\hline CFD & 1.208 & 0.0 & 0.0710 & 0.123 & & 4.012 & & 0.0568 \\
\hline CFD & 1.158 & 0.0 & 0.0603 & 0.0929 & & 2.999 & & 0.0475 \\
\hline CFD & 1.158 & -2.0 & 0.0609 & 0.0935 & & 2.786 & & 0.0342 \\
\hline
\end{tabular}

\section{Jet Profile Comparison}

While the CFD simulations are modeling the jet by setting an internal plenum total pressure and total temperature, it is critical that the flow exiting the slot match the experiment. The internal flow between the first plenum and the second plenum are being modeled in the CFD simulations. Streamlines from the CFD simulations in Fig. 32a show the complex flow in the second plenum where there are two recirculation zones on the top and bottom of the plenum chamber. It is unknown whether this complex flow needs to be modeled or if the flow in the experiment has these same flow features. Since the experiment is being designed for CFD validation, the internal geometry of the model is now being modified in order to minimize the complex flow in the second plenum. New experimental evaluations with the revised model are planned in the near term.

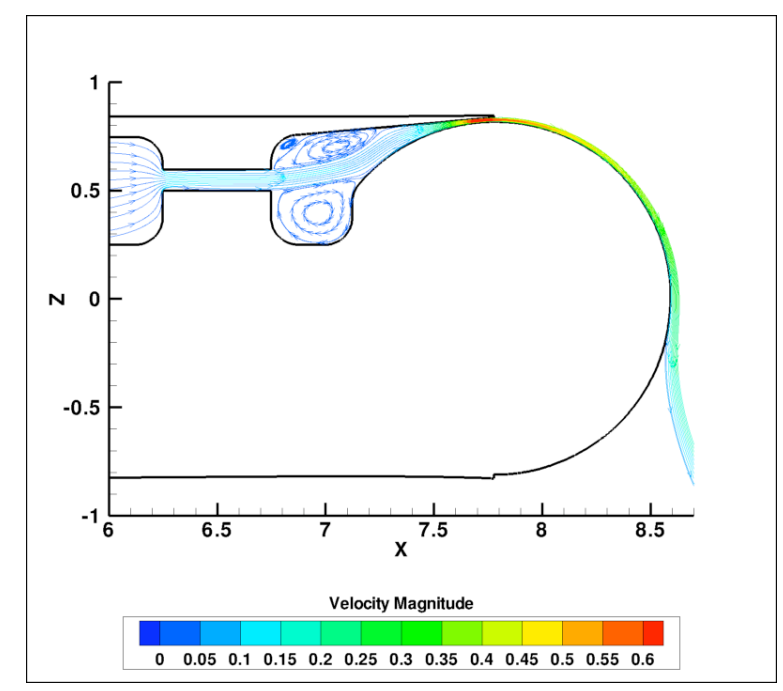

a)

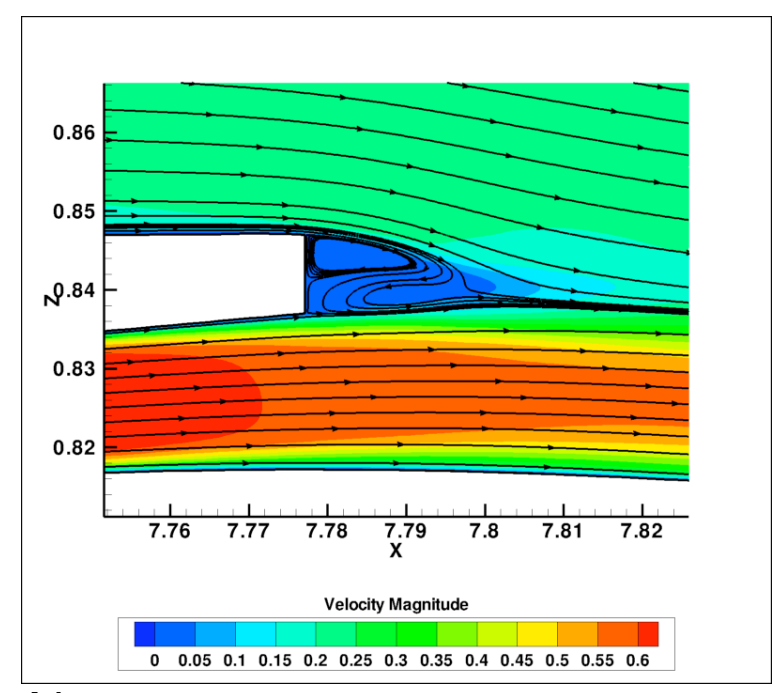

b)

Figure 32- CFD simulation of the circulation control airfoil for a NPR=1.21 and a free-stream Mach number of 0.1 where a) streamlines colored by the velocity magnitude reveal the complex flow in the second plenum and b) shows a close-up view of the slot exit with streamlines and contours of the velocity magnitude, highlighting a small separation zone. 
To verify the slot velocities from the CFD simulations, detailed hot-wire measurements were made at the slot exit with the model on bench top where very accurate measurements could be made. A close-up view of the slot exit is shown in Fig. 32b with streamlines revealing a small separation zone behind a step from upper airfoil skin (the slot lip).

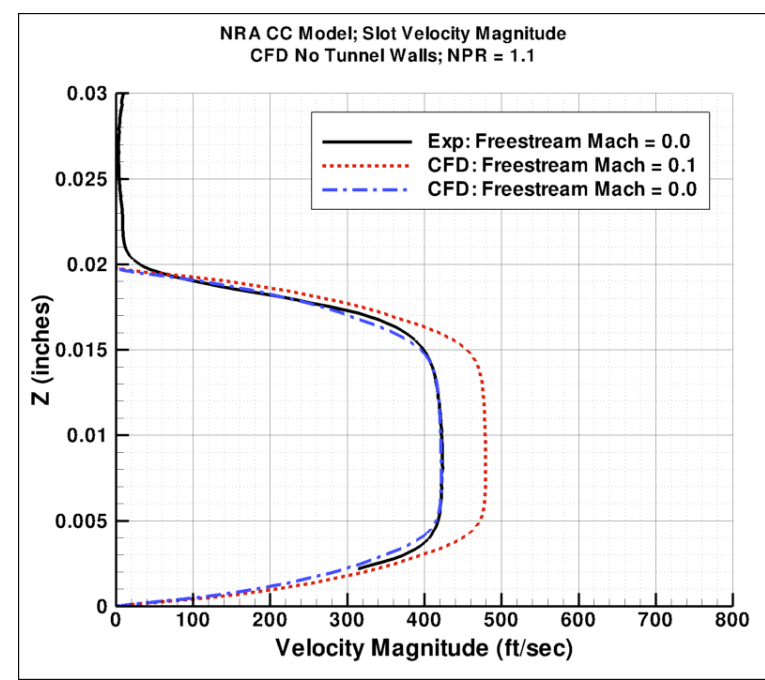

a)

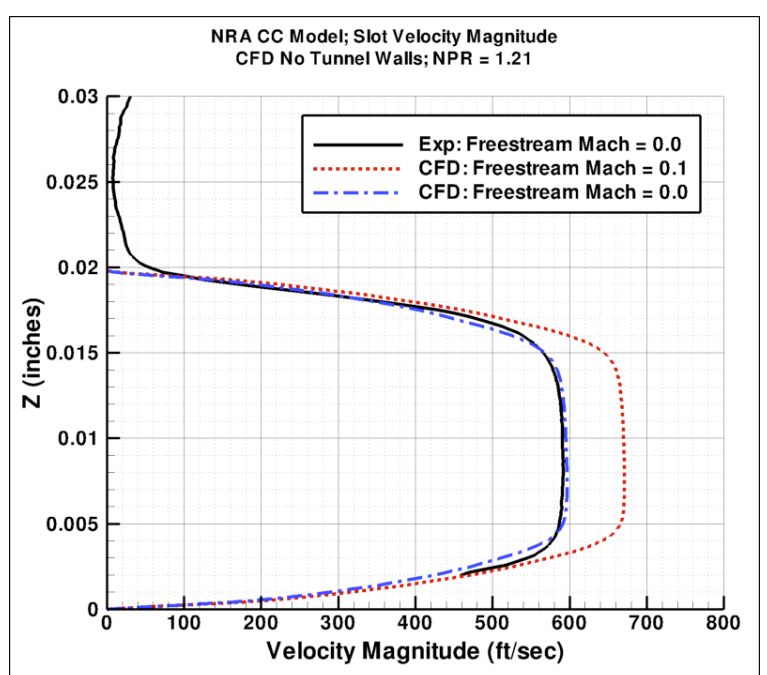

b)

Figure 33- Slot velocity profiles at the slot exit for the CFD and experiment bench top measurements at a) an $N P R=1.10$ and $b$ ) $N P R=1.21$. CFD Simulations for a quiescent flow case (free-stream Mach=0) and an external flow case (free-stream Mach=0.1) are both compared to the bench top hot-wire measurements which had no external flow.

Numerical simulations matching the blowing conditions for the hot wire measurements were made and compared to the experimental results in Fig. 33. Initially the CFD simulations included an external flow with at free-stream Mach number of 0.1. The profiles from the CFD show a significantly larger jet velocity for the same jet nozzle pressure ratio (NPR) and total temperature. Since the bench top measurements did not have an external flow, a second CFD simulation using a quiescent flow (Mach $=0$ ) condition was performed, showing an almost exact match of the measured slot velocity profile. Figure 33a shows a low-blowing case at an $\mathrm{NPR}=1.10$ and Fig. $33 \mathrm{~b}$ a higher-blowing case at $\mathrm{NPR}=1.21$. The comparisons also show a good match of the slot height between the CFD and the experiment. It is speculated that the difference between the jet peak velocity with and without the exterior flow is a result of the suction produced external to the slot exit as a result of the lift generated when there is an external freestream flow.

Comparisons of the mass flow rates between the CFD and experiment, with and without external flow, are shown in Fig. 34. This figure shows that both the experiment and CFD have higher mass flow rates at a given NPR with an exterior flow as compared to bench top case. The plot also shows that the CFD is matching the mass flow rates of the experiment very well for both the quiescent and external flow cases. This comparison shows the influence of the external flow on the slot peak velocity, however the velocity profile seems unaffected by the external flow for the Mach $=0.1$ case. Therefore jet peak velocity measurements need to be made in the tunnel in order to validate the CFD jet velocity profiles. 


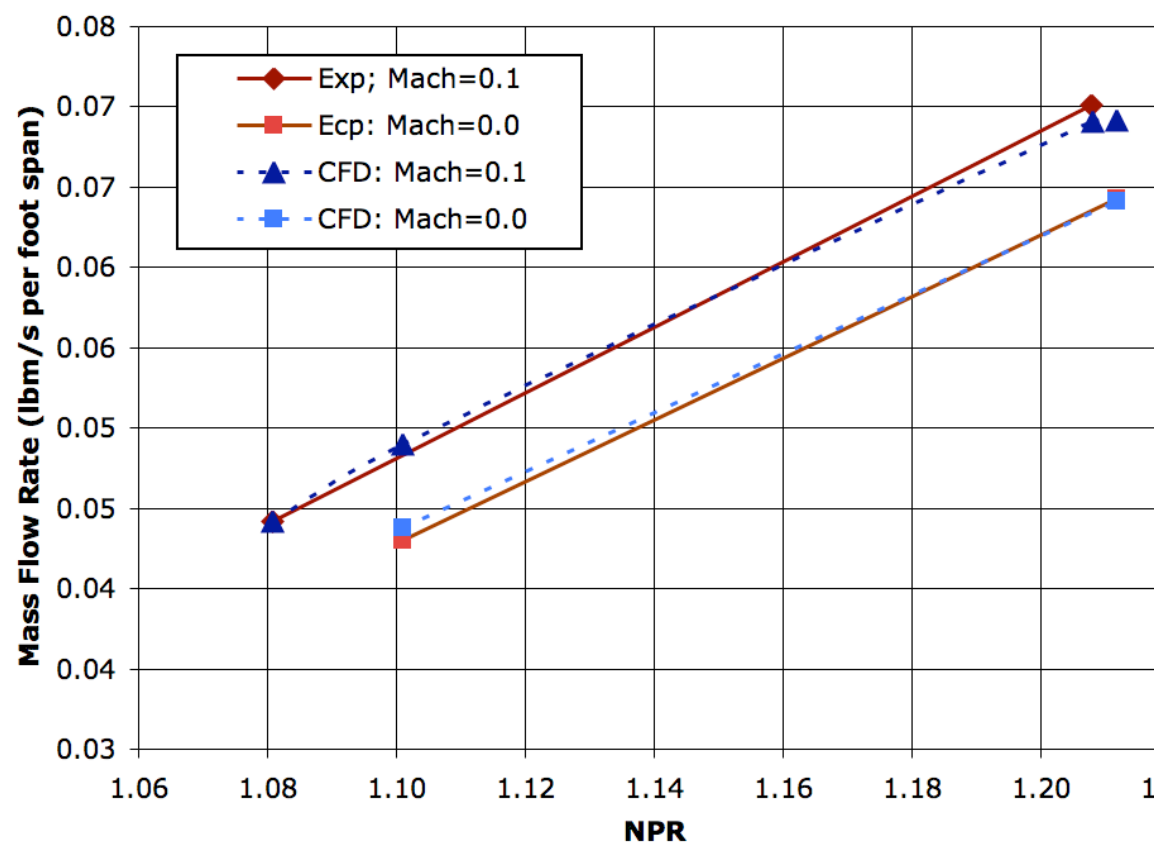

Figure 34. Mass flow rate comparison between CFD and experiment at two

It is thus seen that the CFD and experiment agree in a number of ways, but that future corrections /improvements to both the experimental technique and the CFD may be in order. Additional benchmark data is necessary before the final evaluation of the CFD methods has been confirmed.

\section{Concluding Remarks}

This paper has presented and discussed the significance of results from two benchmark experimental wind-tunnel evaluations that were conducted to provide physics and performance characteristics needed to improve the CFD design tools used for advanced aircraft active-flowcontrol configurations. They have yielded a baseline set of reference data for $\mathrm{CC}$ pneumatic airfoils by which these developing CFD codes can be validated. The experimental data has highlighted the physics of separation and supercirculation related to Circulation Control on highlift and drag-control airfoils. Lift coefficients over 8 at $\alpha=0^{\circ}$ have been demonstrated, as has drag increase or decrease by variation in blowing. The importance of slot height and pressure ratio as control parameters has been demonstrated, as has the significance of leading-edge separation bubbles and flow separation, indicating the need for future control of such in upcoming experimental development. In analysis of the test results, existing CFD codes were employed to assist in evaluation of certain tunnel effects, such as wall interference, wall juncture flows, possible 3-dimensionality, and resulting induced downwash (reduced angle of attack). The present experimental data from two corresponding tunnel evaluations of the same CC airfoil model provide a validation database for NASA's 2-D Circulation Control CFD validation effort. They also suggest improvements in future planned experimental evaluations relating to leadingedge separation control and higher-speed cruise efficiency. 


\section{References}

1. Englar, Robert J., "Overview of Circulation Control Pneumatic Aerodynamics: Blown Force and Moment Augmentation and Modification as Applied Primarily to Fixed-Wing Aircraft," Paper \#2 presented at the NASA/ONR Circulation Control Workshop, Hampton, VA, March, 2004. Also published in Workshop Proceedings, NASA CP 2005-213509, 2005.

2. Englar, Robert J., "Circulation Control Pneumatic Aerodynamics: Blown Force and Moment Augmentation and Modification; Past, Present and Future," AIAA Paper 2000-2541, presented at AIAA Fluids 2000 Meeting, Denver, CO, June 19-22, 2000.

3. Jones, G.S, J.C. Lin, B.G. Allan, W.E. Milholen, C.L. Rumsey, R.C. Swanson, "Overview of CFD Validation Experiments for Circulation Control Applications at NASA," International Powered Lift Conference, London, July, 2008.

4. Rogers, R.O., and M.J. Donnelly, "Characteristics of a Dual-Slotted Circulation Control Wing of Low Aspect Ratio Intend for Naval Hydrodynamic Applications," AIAA Paper 20041244, Reno, Jan 5-8, 2004.

5. Englar, Robert J. and Robert M. Williams, "Test Techniques for High Lift Two- Dimensional Airfoils with Boundary Layer and Circulation Control for Application to Rotary Wing Aircraft," Canadian Aeronautics and Space Journal, Vol. 19, No. 3, pp. 93-108, March, 1973.

6. Englar, R. J., "Circulation Control Aerodynamics for Very Efficient High-lift and Cruise Performance for Subsonic/Transonic Air Vehicles," Year 2 Annual Progress Report for NASA Cooperative Agreement NNX07AB44A, GTRI Project D-5268, Nov. 19, 2008.

7. Buning, P. G., Jespersen, D. C., Pulliam, T. H., Klopfer, W. M., Chan, W. M., Slotnick, J. P., Krist, S. E., and Renze, K. J., "OVERFLOW User's Manual Version 1.8m," Tech. rep., NASA Langley Research Center, 1999.

8. Jespersen, D., Pulliam, T., and Buning, P., "Recent Enhancements to OVERFLOW," AIAA paper 97-0644, January 1997.

9. Pulliam, T. H. and Chaussee, D. S., "A Diagonal Form of an Implicit ApproximateFactorization Algorithm," Journal of Computational Physics, Vol. 39, February 1981, pp. 347-363.

10. Steger, J. L., Dougherty, F. C., and Benek, J. A., "A Chimera Grid Scheme," Advances in Grid Generation, edited by K. N. Ghia and U. Ghia, Vol. 5 of FED, ASME, New York, NY, 1983.

11. Murphy, K., Buning, P., Pamadi, B., Scallion, W., and Jones, K., "Status of Stage Separation Tool Development for Next Generation Launch Technologies," AIAA paper 04-2595, June 2004.

12. Menter, F. R., 'Improved Two-Equation Turbulence Models for Aerodynamic Flows," NASA TM 103975, 1992.

13. Chan, W. M. and Gomez, R. J., "Advances in Automatic Overset Grid Generation Around Surface Discontinuities," AIAA Paper 99-3303, July 1999.

14. Swanson, R. C., and Rumsey C. L., "Numerical Issues for Circulation Control Calculations," AIAA Paper 06-3008, June 2006.

\section{Primary Author, Point of Contact:}


Robert J. Englar, Principal Research Engineer

Acting Chief, Aerospace \& Acoustics Technology Division

Georgia Tech Research Institute

Aerospace, Transportation \& Advanced Systems Lab

Atlanta, GA 30332-0844

404-407-6222, Office

404-407-7586, Wind Tunnel

404-407-8077, Fax

bob.englar@gtri.gatech.edu 